Document downloaded from:

http://hdl.handle.net/10251/60267

This paper must be cited as:

Nerva, J.; Genzale, CL.; Kook, S.; García Oliver, JM.; Pickett, LM. (2013). Fundamental spray and combustion measurements of soy methyl-ester biodiesel. International Journal of Engine Research. 14(4):373-390. doi:10.1177/1468087412456688.

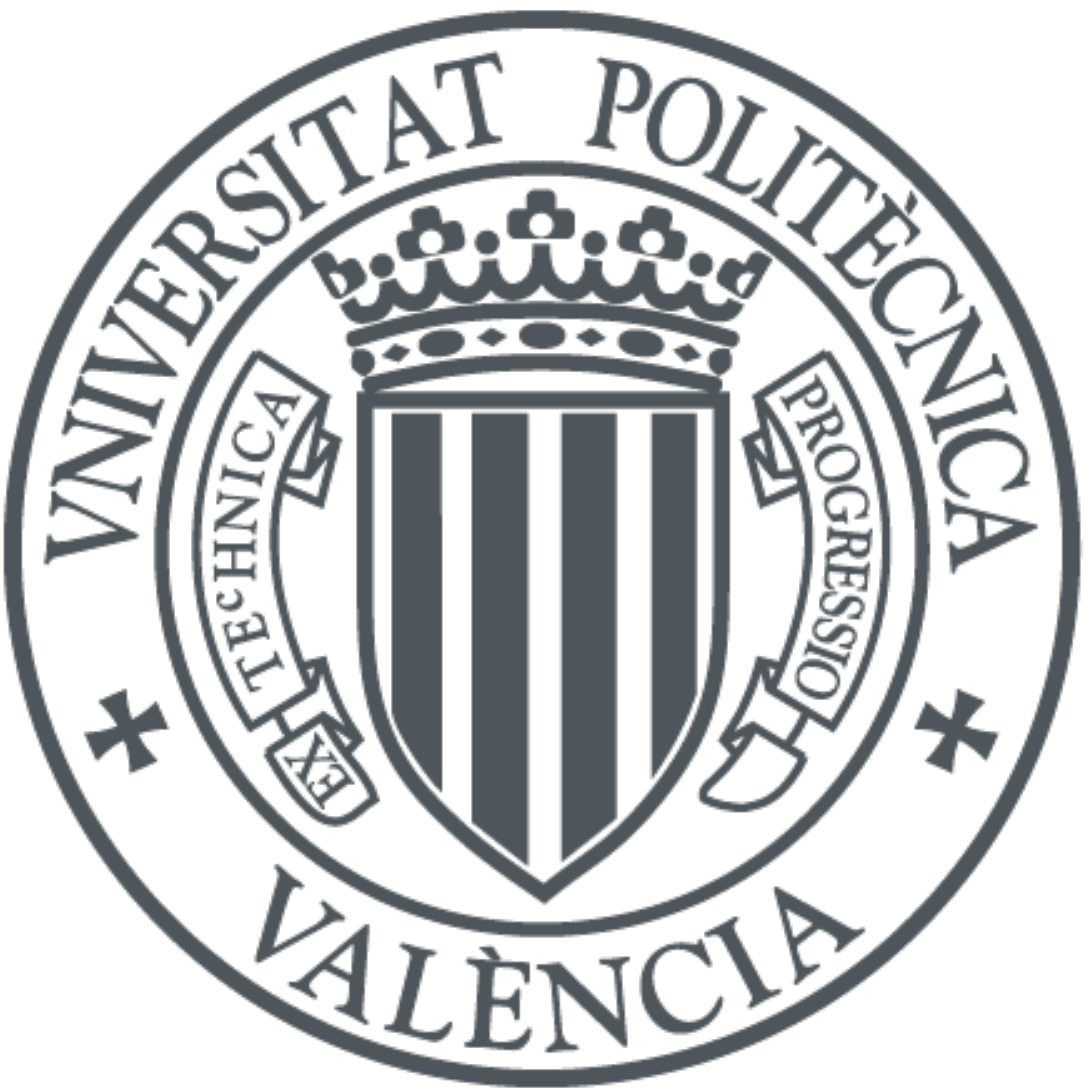

The final publication is available at

http://dx.doi.org/10.1177/1468087412456688

Copyright SAGE Publications (UK and US)

Additional Information 


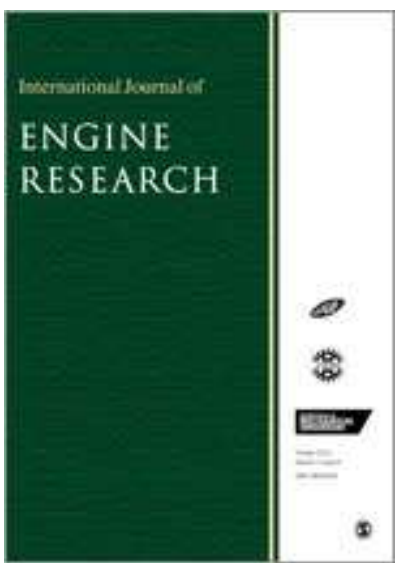

\section{Fundamental Spray and Combustion Measurements of Soy Methyl-Ester Biodiesel}

\begin{tabular}{|c|c|}
\hline Journal: & International Journal of Engine Research \\
\hline Manuscript ID: & Draft \\
\hline Manuscript Type: & Standard Article \\
\hline $\begin{array}{r}\text { Date Submitted by the } \\
\text { Author: }\end{array}$ & $\mathrm{n} / \mathrm{a}$ \\
\hline \multirow[t]{3}{*}{ Complete List of Authors: } & $\begin{array}{l}\text { Nerva, Jean-Guillaume; Universidad Politécnica de Valencia, CMT - } \\
\text { Motores Térmicos } \\
\text { Genzale, Caroline; Georgia Institute of Technology, Department of } \\
\text { Mechanical Engineering } \\
\text { Kook, Sanghoon; University of New South Wales, School of } \\
\text { Mechanical and Manufacturing Engineering } \\
\text { García-Oliver, José; Universidad Politécnica de Valencia, CMT - } \\
\text { Motores Térmicos } \\
\text { Pickett, Lyle; Sandia National Laboratories, Engine Combustion }\end{array}$ \\
\hline & $\begin{array}{l}\text { biodiesel, soy methyl-ester, combustion, free spray, liquid length, } \\
\text { spray penetration, lift-off, soot volume fraction, laser extinction, } \\
\text { planar laser-induced incandescence }\end{array}$ \\
\hline & $\begin{array}{l}\text { Though biodiesel has begun to penetrate the fuel market, its effect } \\
\text { on injection processes, combustion, and emissions formation under } \\
\text { diesel engine conditions remains somewhat unclear. Typical tailpipe } \\
\text { measurements from engines running biodiesel indicate that PM, CO } \\
\text { and UHC are decreased, whereas NOx emissions tend to be } \\
\text { increased. However, these observations are the result of complex } \\
\text { interactions between physical and chemical processes occurring in } \\
\text { the combustion chamber, for which understanding is still needed. } \\
\text { To characterize and decouple the physical and chemical influences of } \\
\text { biodiesel on spray mixing, ignition, combustion and soot formation, a }\end{array}$ \\
\hline
\end{tabular}


soy methyl-ester biodiesel is injected into a constant-volume combustion facility. A range of optical diagnostics is performed, comparing biodiesel to a conventional \#2 diesel at the same injection and ambient conditions.

Schlieren imaging shows virtually the same vapor-phase penetration for the two fuels, while simultaneous Mie-scatter imaging shows that the maximum liquid-phase penetration of biodiesel is higher than diesel due to their different boiling-point temperatures. But the different liquid-phase penetration does not affect overall mixing rate and downstream vapor-phase penetration because each fuel spray has similar momentum and spreading angle. The ignition delay and lift-off length are only slightly less for biodiesel compared to diesel, consistent with the CN. Because of the similarity in lift-off length, the differences in equivalence ratio distribution at the lift-off length are mainly affected by the fuels oxygen content. For biodiesel, the equivalence ratio is reduced, which, along with the fuel molecular structure and oxygen content, significantly affects soot formation downstream. Spatially-resolved soot volume fraction measurements obtained by combining laser extinction measurements with planar laser-induced incandescence imaging show that the soot concentration can be reduced by an order of magnitude for biodiesel. These integrated measurements of spray mixing, combustion, and quantitative soot concentration provide new validation data for the development of CFD spray, combustion, and soot formation models suitable for the latest biofuels.

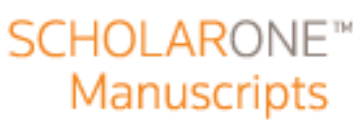




\title{
Fundamental spray and combustion measurements of soy methyl-ester biodiesel
}

\author{
Jean-Guillaume Nerva ${ }^{I}$, Caroline L Genzale ${ }^{2}$, Sanghoon Kook$^{3}$, José M García-Oliver ${ }^{l}$ and Lyle M \\ Pickett $^{4}$ \\ 1: CMT-Motores Térmicos, Universidad Politécnica de Valencia, Spain \\ 2: Department of Mechanical Engineering, Georgia Institute of Technology, USA \\ 3: School of Mechanical and Manufacturing Engineering, University of New South Wales, Australia \\ 4: Combustion Research Facility, Sandia National Laboratories, USA
}

\section{Corresponding author:}

Jean-Guillaume Nerva, CMT-Motores Térmicos, Universidad Politécnica de Valencia, Edificio 6D, Camino de Vera s/n, Valencia 46022, Spain.

Email: jeaner1@mot.upv.es

\begin{abstract}
Though biodiesel has begun to penetrate the fuel market, its effect on injection processes, combustion, and emissions formation under diesel engine conditions remains somewhat unclear. Typical tailpipe measurements from engines running biodiesel indicate that PM, CO and UHC are decreased, whereas $\mathrm{NO}_{\mathrm{X}}$ emissions tend to be increased. However, these observations are the result of complex interactions between physical and chemical processes occurring in the combustion chamber, for which understanding is still needed.

To characterize and decouple the physical and chemical influences of biodiesel on spray mixing, ignition, combustion and soot formation, a soy methyl-ester biodiesel is injected into a constant-volume combustion facility under diesel-like operating conditions. A range of optical diagnostics is performed, comparing biodiesel to a conventional \#2 diesel at the same injection and ambient conditions.
\end{abstract}

Schlieren high-speed imaging shows virtually the same vapor-phase penetration for the two fuels, while simultaneous Mie-scatter imaging shows that the maximum liquid-phase penetration of biodiesel is higher than diesel. Differences in the liquid-phase penetration are expected because of the different boiling-point temperatures of the two fuels. But the different liquid-phase penetration does not affect overall mixing rate and downstream vapor-phase penetration because each fuel spray has similar momentum and spreading angle. For the biodiesel and diesel samples used in this study, the ignition delay and lift-off length are only slightly less for biodiesel compared to diesel, consistent with the fuel cetane number ( 51 for biodiesel, 46 for diesel). Because of the similarity in lift-off length, the differences in equivalence ratio distribution at the lift-off length are mainly affected by the oxygen content of the fuels. For biodiesel, the equivalence ratio is reduced, which, along with the fuel molecular structure and oxygen content, significantly affects soot formation downstream. Spatially-resolved soot volume fraction measurements obtained by combining line-of-sight laser extinction measurements with planar laser-induced incandescence imaging show that the soot concentration can be reduced by an order of magnitude for biodiesel. These integrated 
measurements of spray mixing, combustion, and quantitative soot concentration provide new validation data for the development of CFD spray, combustion, and soot formation models suitable for the latest biofuels.

\section{Introduction}

The diversification of fuel resources, including renewable fuels such as biodiesel $[1,2]$, presents an opportunity and challenge for the control of diesel combustion emissions. The use of biodiesel, in particular, has been studied in multi-cylinder diesel engines in pure and blended formulations, with the majority of these studies reporting a reduction of $\mathrm{PM}, \mathrm{CO}$, and $\mathrm{UHC}$, while $\mathrm{NO}_{\mathrm{X}}$ emission and fuel consumption increase [3, 4]. These emissions trends are the result of complex interactions between physical and chemical processes occurring in the combustion chamber. Fatty-Acid Methyl Ester (FAME) biodiesel has significantly different physical properties compared to regular diesel fuel, including a higher boiling-point temperature, viscosity, and density. In addition, FAME biodiesel is an oxygenated fuel, affecting fuel chemistry as well as air-fuel mixing stoichiometry. Because of the complexity of the physical and chemical interactions that take place during diesel combustion, changes in the spray combustion physics induced by the injection of biodiesel instead of conventional diesel, are not completely understood.

Regarding the physical mixing processes, the quasi-steady liquid penetration, or liquid-length (LL) of biodiesel sprays can be substantially longer than conventional diesel sprays. Recent studies performed under high-temperature, but non-reactive, unsteady conditions showed that biodiesel can increases LL by up to $20 \%$ [5, 6] or $100 \%$ [7] with respect to conventional diesel fuels. This behavior has been related to its higher density and lower volatility [7, 8]. Because of the longer liquid penetration, the proximity of the liquid-phase spray to the quasi-steady flame lift-off length (LOL) is increased, which can potentially modify combustion and emissions formation [10].

Several studies performed under room temperature or low-density conditions (mostly non-evaporative) report a faster axial penetration of the liquid-phase portion of the biodiesel spray [11-13]. Other experiments have shown similar results under comparable or more realistic conditions of a diesel engine [14-16]. However, under these evaporative engine conditions, the vapor-phase penetration of the fuel jet needs to be considered, since this ultimately affects the fuel-ambient mixing rate. But the vapor penetration of a biodiesel jet has not been studied yet in comparison to that of a diesel jet.

In addition, because oxygen-carrying fuels such as biodiesel influence mixture stoichiometry, the temporal and spatial locations of ignition and flame-stabilization can occur differently for biodiesel than for conventional diesel fuels [17]. As flame lift-off determines the extent of oxygen entrainment from the surrounding gases prior to reaction, thereby affecting soot formation, this issue is especially important. Since the stoichiometric mixture fraction is higher for oxygenated fuels, the flame position is expected to occur closer to the center of the fuel jet [17], and the flame length will also be less [18]. With the flame closer to the center of the fuel jet there is still limited information in the literature that quantifies LOL's for reacting biodiesel sprays and the mechanisms governing the lift-off stabilization are still unclear to make good predictions [19]. Limited reports, such as [20], have shown biodiesel to have a longer LOL 
than a conventional European diesel for a large range of charge-gas (ambient) temperatures, but there is still not a widespread conclusion on the LOL behavior of biodiesel.

Despite these limited results, the literature suggests that the LOL is highly correlated with the ignition location and timing [21-23]. LOL measurements performed for a large set of oxygenated and nonoxygenated fuels have shown that fuels with a high cetane number $(\mathrm{CN})$ produced both shorter ignition delay (ID) and shorter LOL, especially at low density and/or low temperature ambient conditions [18]. Nonetheless, differences among fuels rather faded as the conditions were shifted to pressures and temperatures more typical of conventional injection strategies (near TDC). A similar analysis may apply in $[24,25]$, but under such a high-temperature and high-density environment, differences were too small to establish such a connection between ID and LOL.

Numerous studies report that lowering the equivalence ratio at the LOL can reduce sooting propensity [10, $17,18,24,30-34]$ and the oxygenated nature of biodiesel offers a mechanism with which to accomplish these leaner equivalence ratios. Recent studies have investigated the effect of biodiesel on PM emissions (primarily soot) compared to conventional diesel using optical research engines [6, 35-41]. These facilities can associate simultaneous measurements of high-speed spatially-integrated natural luminosity (SINL) (usually through a transparent piston), in-cylinder pressure, and engine-out emissions. All report a consistent reduction of PM emissions when biodiesel is injected instead of conventional diesel. The mechanisms behind this reduction, however, are not fully understood. Though an SINL measurement can provide a qualitative measure of in-cylinder soot formation, this technique is not quantitative for soot concentration. This is primarily due to the high dependence of this diagnostic to the soot temperature $\left(>\mathrm{T}^{5}\right)$ while it is merely linear with the soot volume fraction [42]. Therefore, a quantitative assessment of in-cylinder soot formation is needed to help understand the mechanisms behind the biodiesel soot reduction. In addition, a deeper investigation on the relationship between the spray and jet structure, mixture stoichiometry, and combustion progression is needed [37, 43, 44] to develop a complete picture of the physics leading to the soot formation process.

By studying biodiesel sprays under controlled free-jet conditions with multiple diagnostics, the present work addresses the mechanisms for vaporization, mixing, ignition, lift-off length, and soot distribution, providing a more complete understanding of how biodiesel fueling affects these processes. An array of carefully selected optical diagnostics and ambient gas conditions are applied to a single spray plume. To assess the influence of biodiesel fueling on spray and injection behavior, liquid and vapor-phase penetration were visualized using simultaneous Mie-scattering and schlieren high-speed imaging. To decouple physical and chemical processes, the spray was studied under both inert and reactive conditions. High-speed imaging of chemiluminescence, time-sequenced OH-chemiluminescence and Planar LaserInduced Incandescence (PLII) of soot documented the successive stages of the combustion reaction, from the early stages of ignition to the first soot formation. Measurements of the quasi-steady LOL provide the flame morphology, while a combined PLII and line-of-sight laser extinction measurement, provides crosssectional maps of the soot volume fraction field in the quasi-steady combusting spray. These soot volumefraction datasets represent the first quantitative soot measurements within reacting biodiesel sprays at engine conditions available in the literature. Results are compared with those obtained using a conventional US \#2 diesel (D2). A 1-D spray mixing model is also employed to provide predictions of two-dimensional mixture fraction fields, supporting a discussion of the physical mechanisms behind the sooting characteristics of biodiesel. 


\section{Experimental Facility}

\section{Spray Combustion Simulation Facility}

Experiments have been conducted in an optically accessible, constant-volume combustion vessel under simulated, quiescent diesel engine conditions. The vessel has a cubical combustion chamber, $108 \mathrm{~mm}$ on a side. The fuel injector is mounted horizontally in a purposely designed port, on one of the cube faces. Optical access is provided through sapphire windows located in four other ports allowing line-of-sight and orthogonal optical access to the spray. Previous publications provide in-depth discussions of the combustion vessel $[45,46]$ and the procedure for simulating diesel conditions [10, 45-48].

To summarize, the procedure is started by filling the vessel to a specified density with a premixed, lean combustible-gas mixture. This mixture is then ignited with spark plugs and burned, creating a hightemperature, high-pressure environment in the vessel. As the products of combustion cool over a relatively long time $(\sim 1 \mathrm{~s})$ due to heat transfer to the vessel walls, the vessel pressure slowly decreases. When the desired pressure is reached, the diesel-fuel injector is triggered and the fuel injection, auto-ignition and combustion processes ensue. Throughout an experiment, the mixing fan at the top of the combustion chamber is active. This fan maintains a spatially uniform temperature environment $( \pm 2 \%)$ in the combustion vessel up to the time of diesel fuel injection. The gas velocities induced by the fan $(\sim 1 \mathrm{~m} / \mathrm{s})$ are small in comparison to the velocities of the fuel jet $[10,48]$. For the conditions of this paper, the jet penetration velocities exceed $75 \mathrm{~m} / \mathrm{s}$ at a position midway through the chamber. As a result, the gases in the chamber can be considered quiescent relative to the fuel jet. The temperature, density, and composition of the ambient gas in the vessel at the time of diesel fuel injection can be varied widely with this simulation procedure. The ambient gas temperature and density at injection are determined by the ambient gas pressure at the time the fuel injector is triggered and the mass of the gas initially put in the vessel (a constant up to the time of the diesel injection event).

As shown in Table 1, two levels of ambient temperature at constant density were selected for experimentation. The ambient composition is determined by the composition of the combustible gas mixture burned to generate diesel-like temperatures and pressures. First, the oxygen content was set to 0\% avoiding any reaction and allowing the analysis of physical processes involved in the fuel injection only. Then, a reactive environment $\left(15 \% \mathrm{O}_{2}\right)$ was created using a leaner premixed combustion, simulating air diluted with EGR. This enabled the analysis of the association between physical and chemical processes.

\section{Injector}

The fuel injector geometry and operating conditions are summarized in Table 2 . The injector has a singlehole, axial nozzle and is connected to a standard common rail in which pressure was controlled to 150 MPa throughout the experiment. The nominal nozzle-hole diameter is specified at $90 \mu \mathrm{m}$, with microscopy imaging showing that the mean diameter is near $91 \mu \mathrm{m}$. Further information on the injector and its mounting may be found in the "Fuel injector and rail setup" section of the "Spray A" configuration of the Engine Combustion Network, an international collaborative group investigating diesel engine combustion fundamentals [49].

\section{Fuels}


To provide context to our examination of the mixing and combustion behavior of biodiesel in this work, we performed comparative measurements using a conventional U.S. \#2 diesel fuel. The properties of the soy-derived biodiesel, together with those of the conventional U.S. \#2 diesel used in the experiments, are given in Table 3. Biodiesel is oxygenated, as reflected by its higher stoichiometric mixture fraction $\left(\mathrm{Z}_{\text {stoich }}\right)$ and its lower energetic content, expressed as the Lower Heating Value (LHV). The FAME composition of the biodiesel fuel sample is given in Table 4. The possible effects of its higher density and viscosity on injection processes have been investigated by measuring the mass rate of injection as shown in Figure 1. Biodiesel has a slightly higher mass flow rate, partially explained by the higher fuel density. Considering the energy rate of injection, the higher mass flow rate does not entirely offset the lower LHV. Consequently, biodiesel injections were extended to deliver the same total energy at each injection. The injected mass of biodiesel was $22.7 \mathrm{mg}$ while it was $19.7 \mathrm{mg}$ for \#2 diesel.

The distillation curves obtained under ASTM standards are presented graphically for both fuels in Figure 2. As seen in Figure 2, biodiesel has a relatively flat distillation curve compared to diesel. The higher distillation temperatures over the full range of fuel recovery also shows that most of the conventional diesel fractions vaporize at temperatures lower than biodiesel under atmospheric pressure. This trend is expected for a spray under higher ambient pressure, making complete vaporization more difficult for biodiesel.

\section{Optical diagnostics}

Two sets of optical techniques have been employed in the current work. The first setup is aimed at characterizing the fuel mixing processes under both inert and reactive environments using simultaneous Mie-scattering and schlieren visualization, while the second was intended to quantify soot formation, using simultaneous laser extinction, planar laser-induced incandescence, and visualization of chemiluminescence ( $\mathrm{OH}$ and other). Details of each setup are listed in Table 5 and explained below.

\section{Fuel/Ambient mixing setup}

Simultaneous Mie-scattering and schlieren high-speed imaging was used to assess the temporal and spatial relationship between the liquid and vapor phases of the spray. The arrangement of the optical devices used for these measurements is shown in Figure 3.

A 100-mm wide and 20-mm oval-shaped laser beam, proceeding from a continuous-wave laser was directed downstream of the injector to volume illuminate the spray. Mie-scattered light from liquid droplets was collected by a high-speed CMOS camera at 50,000 pictures per second. The optical setup intentionally saturated the camera sensor (12 bits/4096 digital levels) in the dense liquid region, providing higher sensitivity to regions of complete vaporization. The image processing of this diagnostic aimed at measuring the maximum liquid-phase penetration (or liquid length). The threshold to apply for image segmentation is discussed and validated with laser extinction measurements in the Results and Discussions section.

Simultaneous to the Mie-scatter imaging, schlieren high-speed imaging enabled visualization of refractive index gradients at the boundary between vaporized fuel and hotter ambient gases [51]. The schlieren setup is described in more detail in Ref. [50]. Its purpose was to obtain time-resolved measurement of the vaporphase penetration of the spray, which requires special image processing. A code available online at [49] has been developed to analyze the texture of the schlieren sequence. One option detects changes in texture 
produced by the moving jet, allowing the vaporized fuel jet to be more easily identified against a nonuniform, but frozen, background [50,60]. Once the jet boundaries are obtained, the penetration of the leading edge is calculated using the method defined by Naber and Siebers [48].

\section{Combustion and soot measurement setup}

The optical combustion diagnostics employed for this study include high-speed broadband chemiluminescence imaging, intensified $\mathrm{OH}$-chemiluminescence imaging, planar laser-induced incandescence (PLII) imaging, and laser extinction measurements. The laser extinction technique is shown with emphasis in Figure 4. These diagnostics were all applied during the same injection event by arrangement of cameras/beamsplitters/mirrors and viewing through the bottom window depicted in Figure 3.

High-speed images of natural combustion luminosity were collected to characterize the high-temperature ignition processes as in $[21,53]$. Some time after ignition, strong emission from soot incandescence would eventually saturate the luminosity imaging. To measure the upstream high-temperature reaction zone without interference from soot luminosity, $\mathrm{OH}$-chemiluminescence imaging was performed using an intensified CCD camera as shown in Table 5. Beginning after autoignition and jet stabilization, the camera gate time opened for $3 \mathrm{~ms}$ to obtain time-averaged images, allowing identification of the quasisteady lift-off location of the reacting jet as in $[10,54]$. In other experiments, the camera timing was varied to find the first appearance of $\mathrm{OH}$-chemiluminesence in concert with broadband luminosity imaging. The camera gate was reduced to $200 \mu \mathrm{s}$, accompanied by increased camera gain.

PLII images of soot were collected to analyze the location of soot along a thin plane at the jet axis. A frequency-doubled Nd:YAG laser pulse was used for this measurement. Images were acquired at $4 \mathrm{~ms}$ ASI during the quasi-steady portion, as well as throughout injection to detect the first appearance of soot. Figure 4 shows that the 80 -mm wide laser sheet passes through the jet axis, creating the laser-generated incandescence signal along a plane. This soot signal was imaged by a second intensified CCD camera, filtering to block the soot luminosity and beam reflections.

Simultaneous to the PLII data acquisition, a helium-neon (HeNe) laser beam was passed through the center of the fuel jet and collected with an integrating sphere to measure the soot or droplet extinction along this beam path. The laser extinction measurement provides the optical thickness, KL, where the transmitted laser intensity, I, normalized by the baseline laser intensity, $\mathrm{I}_{0}$, is related to the KL such as:

$$
I / I_{b}=e^{-x I}
$$

In Eq. (1), $\mathrm{K}$ is the extinction coefficient and $\mathrm{L}$ is the path length through the soot cloud. The KL was time-averaged between 3 and $7 \mathrm{~ms}$ ASI during the quasi-steady period. All the technical considerations relative to this technique may be found in [55], including special considerations needed to accommodate high beam steering caused by fuel vaporization and combustion in this pressurized environment.

As will be shown, the liquid-phase and soot regions were spatially separate from one another, permitting quantitive analysis of the soot field. The laser extinction quantifies the soot opacity integrated along the laser path through the jet: 
$\int_{\mathbb{R}}^{-\mathbb{K}} \mathrm{f}_{\mathrm{V}} \frac{k_{e}}{\lambda} d z=K L$

where $R$ is the jet outer radius, $\lambda$ is the laser wavelength $(632.8 \mathrm{~nm})$, and $k_{e}$ is the dimensionless extinction coefficient. A value of $k_{e}=8.7$ was selected to relate the $K L$ to the soot volume fraction [56]. Therefore, PLII images can be used, in combination with the quantitative $K L$ measurements at the jet centerline, to obtain the time-averaged radial soot volume fraction $\left(f_{v}\right)$ distribution upon the fact that the PLII signal is proportional to the soot volume fraction $\left(f_{v}=c\right.$. LII). That is, the calibration constant $c$ can be determined with the measured LII profile, measured $K L$, and known soot optical properties. This, in turn, enables the calculation of the average radial soot volume fraction distribution.

Note that while a quantitative relationship between KL and soot volume fraction is affected by uncertainties in the soot optical properties, a relative comparison between the two fuels under all operating conditions should be valid since the soot optical properties are not expected to change significantly. With KL measurements along the axis of the jet combined with the PLII images, these data were used to obtain quantitative, two-dimensional soot volume fraction distributions, similar to Refs. [34, 57-59].

\section{Results \& discussions}

The Results and Discussions section is divided into three parts to analyze the succession of processes occurring during the combustion of the biodiesel spray. In each section, measurements taken using biodiesel and \#2 diesel are compared to assess the physical and chemical effects of biodiesel on the mixing and combustion processes. In the first section, high-speed imaging of the liquid and vapor penetration of the non-reactive spray are analyzed and contrasted with 1-D jet modeling results. The second section presents high-speed imaging under reactive conditions, providing a temporal and spatial description of ignition and first soot formation. The last section presents time-averaged measurements during quasi-steady combustion to quantify lift-off length and in-flame soot concentration.

\section{Analysis of the transient inert spray}

Imaging of the liquid- and vapor-phase spray was performed in both reacting (15\% oxygen) and inert (0\% oxygen) conditions. Only the inert case will be discussed in this first section. Both fuels were injected into ambient environments of 900 and $1000 \mathrm{~K}$ with equivalent density and injection pressure. Measurements of the liquid-phase penetration were obtained using the image processing algorithm described above. Still, the tip of the liquid spray, where most of the fuel already vaporized but where some small fractions still remain in liquid-phase, has always represented a difficult challenge to resolve via image processing. This concern has been analyzed by moving the HeNe laser, used in subsequent soot extinction measurements, along the vicinity of the liquid spray tip region. By measuring the extinction of the HeNe beam due to scattering by liquid droplets, a threshold for liquid boundary selection in the Mie-scattering images could be justified. The extinction induced by the liquid droplets near the spray tip was quantified following Eq. 1 . 
Figure 5 shows the KL measurements taken at 5 axial positions and the liquid length obtained using 4 different thresholds with their corresponding standard deviation. Although the KL measurements are relatively low compared to what could be found measuring soot, the decrease in KL is appreciable moving the laser from 19 to $21 \mathrm{~mm}$. Mie-scatter processing using a threshold of 120 to 250 pixel counts results in mean liquid lengths of 20 to $21 \mathrm{~mm}$. A value of 120 pixel counts (or $3 \%$ of the maximum signal) to define liquid length was selected for consistency with previous measurements at this facility [45].

The ensemble-averaged liquid penetration of 10 injection cycles is plotted as a continuous line in Figure 6. As expected, the liquid-phase penetration stabilizes at a fixed distance from the injector, which is timeaveraged during the steady period for determination of the mean liquid length (LL), as defined by Siebers in [45]. Considering first the inert condition, biodiesel shows an increased liquid length of about $30 \%$ compared to conventional \#2 diesel at both ambient temperatures. This result is consistent with the higher distillation temperature range for biodiesel shown in Figure 2.

Simultaneous to the Mie-scatter liquid-phase imaging, high-speed schlieren imaging was used to visualize the vapor-phase penetration. In Figure 7, the ensemble-averaged penetration at $900 \mathrm{~K}$ is shown as solid lines. The measured liquid-phase penetration is also shown for reference. During the initial penetration of the injection, the liquid and vapor phases overlap until the liquid-phase reaches its maximum penetration or liquid length. After the spray reaches this penetration distance, only the vapor-phase continues its progression through the chamber up to the vessel wall. The jet slows as it continues to penetrate and entrain ambient gases, following a typical square-root dependency with time [48].

Comparing the two fuels jets, biodiesel appears to have a slightly faster penetration rate than \#2 diesel, demonstrated more easily by the difference in penetration at the top of Figure 7, which shows as much as $2 \mathrm{~mm}$ higher penetration for biodiesel. However, the differences are slight, especially when considering the experimental uncertainty. The shaded line surrounding the mean biodiesel penetration at the bottom is the $95 \%$ confidence interval for the ensemble average of the data. The overlap between mean value and the shaded region shows that the statistical difference between the two fuels is only marginal.

If real, the faster penetration of biodiesel could be the result of two factors: (1) a narrower spreading angle and/or (2) a higher spray momentum. Investigations of the measured spreading angle were not conclusive to establish a spreading angle effect in this study. The difficulties with assigning a spreading angle via schlieren imaging in this high-temperature/high-pressure environment are discussed at length in Ref. [60], where it was shown that subtle differences in optical setup and image processing yield different results for spreading angle but not penetration. Indeed, the radial borders of the schlieren images (see Figure 9, later, as an example) have too much uncertainty to conclude that biodiesel has a smaller spreading angle compared to diesel. However, studies in a low density environment where these uncertainties are smaller were conclusive that biodiesel had a smaller spreading angle than diesel during the transient penetration, before relaxing to the same spreading angle during the steady period [13]. Therefore, although no certain trend with spreading angle can be established in this study, there is an indication that the biodiesel spreading angle may be slightly less than diesel, at least during the initial transient period.

Regarding (2), there is also an indication that biodiesel may have a slightly higher spray momentum. Note that the higher fuel density of biodiesel does not automatically increase spray momentum when injection pressure is held constant [47]. In fact, momentum changes only if the nozzle flow coefficients change. Table 2 indicates that the discharge coefficient increases from 0.91 with diesel to 0.94 with biodiesel, 
indicating that biodiesel would have higher momentum. Uncertainties in these coefficients deserve attention, however, particularly because the fuel and injector temperature were slightly $(10 \mathrm{~K})$ different, which increases the uncertainty. In our previous study [13], flow coefficient measurements performed for the same fuels using the same injector temperature controller, but with a different, 0.108-mm nozzle, showed only an 0.01 units higher nozzle flow coefficients for biodiesel compared to diesel. This difference is also within the experimental uncertainty [13].

Given the uncertainties associated with spreading angle and spray momentum, and also with the measured penetration itself, it is helpful to address the effect that these parameter variations have on predicted jet penetration. The Musculus and Kattke jet model described in [61] is used to model spray penetration with different assumptions for nozzle coefficients and spreading angle. Modeling results are given at the top of Figure 7, displayed as difference in the modeling result compared to the biodiesel experimental or modeling data. Three model predictions are represented in the figure. One is for biodiesel with the discharge coefficient set to the experimental value of Table 2 and a full spray angle of $20^{\circ}$. The model predictions for biodiesel toggle about the experimental data, starting out too low but ending too high, although never varying from the experimental data by more than $2 \mathrm{~mm}$. Two other model predictions are shown for diesel fuel. D2a uses the same spreading angle as BD and the measured discharge coefficient from Table 2, while D2b assumes the same nozzle coefficients and a higher spreading angle. The lower penetration of diesel (positive values in Figure 7, top) is well predicted with either a $0.6^{\circ}$ spreading angle increase or a 0.03 decrease in discharge coefficient (according to our measurements) compared to that of biodiesel, amounting to about $1 \mathrm{~mm}$ lower penetration by $3000 \mu \mathrm{s}$ in each case. This modeling exercise is useful because it shows the extent that changes in spreading angle or flow coefficients affect penetration. It also shows that these subtle variations produce predictions that fall within the experimental uncertainty, as was discussed for a wide range of fuel sprays in [47]. Ultimately, we conclude that the differences in penetration for biodiesel and diesel jets are not significant enough to ascertain a causal effect of either spreading angle or flow coefficients on the penetration.

The penetration measurements do provide a valuable basis for estimation of the fuel/ambient mixing field, or the mixture fraction distribution throughout the jet, because the jet model used for prediction of penetration may also be used for prediction of mixture fraction. Recent work shows that when model predictions are based on the measured penetration the model also falls within the experimental uncertainty of direct mixing measurements [60]. The mixture fraction predictions may be converted to equivalence ratio by considering the ambient oxygen concentration, as well as the fuel oxygen.

The resulting two-dimensional mixing contours of the steady-state, non-reacting jet are represented in Figure 8. Three mixture fraction layers of interest are indicated, including surfaces representing evaporation (liquid length), soot formation (equivalence ratio $=2$ ), and stoichiometry. Note that the model predictions correspond to the best fit of penetration when using experimental nozzle coefficients with constant spreading angle, and include effects such as differences in fuel density. For the liquid length predictions, properties of $n$-heptadecane and methyl-oleate have been selected as surrogates because of their similar physical properties to diesel \#2 and biodiesel, respectively [13, 62]. The mixing predictions provide guidance about mixing and combustion phenomenon that is discussed throughout this paper.

The mixing predictions show that a longer liquid length is predicted for biodiesel, owing to a lower mixture fraction for complete vaporization compared to that of diesel fuel. Although the liquid length does not match the experimental value using a spreading angle input, which appears too high for the near- 
nozzle region, as discussed in Ref. [60], the trends are consistent with the boiling point temperature and fuel density arguments made above. The mixing prediction contours also show that the approximate soot formation limit $\left(Z_{\text {soot }}\right)$ and stoichiometric layer $\left(Z_{\text {stoich }}\right)$ occur further upstream for biodiesel. This is caused directly by fuel oxygenation, which increases the critical mixture fraction for these quantities for biodiesel compared to diesel, as shown in Table 3. Essentially, a higher $\mathrm{Z}_{\text {stoich }}$ or $\mathrm{Z}_{\text {soot }}$ means that less mixing with ambient gases is required to avoid soot formation or to complete combustion.

\section{Analysis of the transient reactive spray}

To examine the ignition and combustion behavior of the biodiesel spray, the operating conditions were modified from the previous non-reacting experiments to generate an ambient oxygen concentration of $15 \%$ (by volume) while maintaining all other thermodynamic conditions. Some observations about the effects of ignition and combustion on liquid-phase penetration were already given in Figure7, where it is shown that there are no significant differences between the inert and reactive spray. These results suggest that the flame heat release does not affect the vaporization processes for either the biodiesel or \#2 diesel sprays at these particular experimental conditions. Understanding the causes for this behavior and further observations of combustion requires analysis of the ignition and reaction zones within the fuel jet.

Figure 9 presents a time sequence of images representing a typical combustion event for a biodiesel spray at the $1000 \mathrm{~K}$ operating condition. To reveal lower intensity regions during the early stages of ignition and combustion, the range of image display is shown as a percentage of full scale for some natural luminosity and PLII images, as indicated in the lower right of these images. The figure shows that the first appearance of broadband chemiluminescence occurs simultaneously with $\mathrm{OH}$-chemiluminescence at 400 $\mu \mathrm{s}$, indicating that the broadband chemiluminescence is a capable marker of high-temperature, secondstage ignition [22]. Spatially, the first broadband and $\mathrm{OH}$ chemiluminescence appears in the head vortex region of the spray, which is also the same location where a noticeable darkening and radial expansion appears in the schlieren image, signifying a rapid decrease in density [46,50]. After ignition, the reaction zone grows and expands in all directions, filling the downstream portion of the jet and also moving slightly upstream. However, the $\mathrm{OH}$ chemiluminescence shows that the flame remains lifted from the injector during subsequent injection at slightly less than $20 \mathrm{~mm}$ from the injector.

To quantify the average ignition timing and location, the first broadband chemiluminescence detection was identified (intensity $>4 / 4096$ counts). Afterwards, the ignition location was more precisely defined as the centroid of the chemiluminescence area for the next three subsequent images. The ensemble-average ignition delay and axial position over a large number of combustion events are given in Table 6. For biodiesel, ignition delay nearly doubles, and the ignition site moves downstream, comparing results at 900 $\mathrm{K}$ to that at $1000 \mathrm{~K}$. These results emphasize the strong influence of ambient temperature in the processes governing autoignition.

The pressure signal offers a second measure of the ignition delay. Pressure measurements typically show a sharp increase corresponding to the onset of rapid, second-stage ignition [49]. The timing of this rapid pressure increase was identified, and also corrected for speed-of-sound time delay to reach the pressure transducer [21]. A comparison of the broadband chemiluminescence and pressure signal detection of ignition in Table 6 shows that the two ignition delay metrics are consistent, indicating straightforward interpretation of ignition based on the imaging (schlieren, broadband, $\mathrm{OH}$ chemiluminescence) observations. Evaluation of the measured ignition delays for biodiesel and \#2 diesel shows that biodiesel 
ignites faster than conventional \#2 diesel, in agreement with the cetane numbers indicated in Table 3. Differences in ignition delay for the two fuels also influence the stabilized lift-off length position, as discussed in the next section.

The penetration rate of the reacting fuel jet is demarcated by the green border lines overlaid on the schlieren images of Figure 9. The ensemble-average penetration for the biodiesel jet is shown in Figure 10 , where reacting results are shown alongside inert to highlight differences attributed to heat release. In addition, the spatially integrated intensity obtained from broadband chemiluminescence imaging is plotted on a logarithmic scale on the right axis. A star on the figure indicates the time of first pixel saturation due to intense soot luminosity, evident in the bottom images of Figure 9, after which the intensity is no longer quantitative. The objective of Figure 10 is twofold: First, it shows that combustion affects penetration; Second, it illustrates that the timing of the combustion interaction effect on penetration is different for each ambient temperature, as indicated by the presence of broadband chemiluminescence emission.

The penetration for the non-reactive $1000 \mathrm{~K}$ jet (900 K data is presented in Figure 7) is nearly identical to that of the $900 \mathrm{~K}$ condition, as shown plainly in Figure 10. This behavior is expected because ambient temperature is known to have no effect on vapor-phase penetration under inert conditions [48, 63]. However, under reactive conditions, the jet is faster in reaching the wall. Moreover, this acceleration of the jet tip is amplified when ambient temperature is increased. Faster penetration of a reacting jet may be expected because heat release reduces the density of the jet, and causes thermal expansion [64,65]. However, since this expansion also occurs in the radial direction, the axial expansion (penetration) may or may not exceed that of the non-reacting jet $[65,50]$, depending upon particular conditions.

Regarding soot formation, Figure 9 shows that the first detectable LII signal occurs after $600 \mu$ s ASI for biodiesel, more than $200 \mu \mathrm{s}$ after the start of high-temperature combustion. Soot concentrations are very low at first; the 10\%-scale display-adjusted image shows that the first soot develops at approximately 32 $\mathrm{mm}$ from the injector tip which corresponds to the transient head vortex region according to the schlieren and chemiluminescence images. Bright luminosity from hot, naturally incandescent soot is also apparent in this head region in the luminosity and schlieren images, also signifying that soot has formed. A finite time delay between high temperature ignition and soot formation has been demonstrated previously [66], particularly for fuels with lower sooting propensity operating in reduced ambient oxygen concentration (i.e., $15 \% \mathrm{O}_{2}$ ) environments.

After the time of initial soot formation, the sooting region follows the jet development downstream and soot concentration increases by more than a factor of 10 , based on the PLII intensity scale. The sooting zone remains about $10 \mathrm{~mm}$ downstream of the lift-off length and does not regress back towards the injector. At steady conditions (after $4000 \mu \mathrm{s} \mathrm{ASI}$ ), the soot concentration decreases downstream of $80 \mathrm{~mm}$ where enough oxygen has been entrained to oxidize the soot. In the following analysis, the soot formation is examined and compared in biodiesel and diesel sprays during this quasi-steady combustion period, downstream of the stabilized, lifted flame.

\section{Analysis of soot formation for stabilized flame}

Long injection events were studied to quantify the soot formation of the fully developed biodiesel and \#2 diesel sprays during the mixing-controlled phase of combustion. As previously discussed, a combination of PLII and laser extinction measurements was performed to produce 2-dimensional maps of the soot 
volume fraction at the jet center plane. The stabilized lift-off length position was also measured during the quasi-steady period to assess the spatial relationship between lift-off length and soot formation for the two fuels.

The stabilized lift-off length was measured from $\mathrm{OH}$-chemiluminescence images using a long-duration exposure centered during the quasi-steady period. Figure 11 shows the ensemble average of numerous cycles and the resulting averaged lift-off length. Consistent with the observation of a slightly shorter ignition delay for biodiesel, a decrease in the lift-off length is also observed for biodiesel in comparison to \#2 diesel. The order for both ignition delay and lift-off length is as follows: $\mathrm{BD}(1000 \mathrm{~K})<\mathrm{D} 2(1000 \mathrm{~K})<<$ $\mathrm{BD}(900 \mathrm{~K})<\mathrm{D} 2(900 \mathrm{~K})$.

To quantify the soot formed during the quasi-steady period, line-of-sight laser extinction measurements were performed along the flame axis, at least every $10 \mathrm{~mm}$ from $30 \mathrm{~mm}$ to $80 \mathrm{~mm}$. The calculated optical thickness, KL, at each axial position was time-averaged over the stabilized portion of the extinction signal, between 3000 and $7000 \mu$ s ASI (during the quasi-steady period), and ensemble-averaged for 10 injections. Figure 12 shows results for biodiesel and \#2 diesel [49] sprays at the $900 \mathrm{~K}$ and $1000 \mathrm{~K}$ ambient conditions. The tendency for biodiesel to form less soot than conventional diesel is in agreement with exhaust measurements as discussed in the Introduction [3, 4]. Levels are very low for biodiesel at $900 \mathrm{~K}$, with peak KL values less than 0.01 , but both PLII and laser extinction confirm that some soot does form at this condition. The axial distribution shows that soot formation reaches a peak at 50 or $60 \mathrm{~mm}$ before decreasing as soot oxidation becomes dominant towards the flame length. The peak soot location tends to move further downstream with decreasing ambient temperature, in response to an increased lift-off length and delayed soot formation $[17,18]$.

To give further insight into the soot spatial distribution, the qualitative PLII images were combined with the quantitative KL measurements to construct the 2D maps of soot volume fraction as shown in Figure 13. Note that different color scales are used because of the large change in soot level. Results show that the use of biodiesel instead of \#2 diesel reduces local soot concentration by a factor 5 at $1000 \mathrm{~K}$ and by a factor 10 at $900 \mathrm{~K}$. Biodiesel soot is also more constrained to the center of the fuel jet, and the axial position of what appears to be complete oxidation (i.e., the flame length) is also is shorter.

Causes for the change in soot distribution for oxygenated fuels were examined in [17], and these factors remain important for biodiesel fuel. As was shown in the jet mixture fraction predictions given in Figure 8 , the oxygen content of biodiesel increases the critical mixture fraction for the soot formation limit $\left(\mathrm{Z}_{\text {soot }}\right)$ and the stoichiometric layer $\left(Z_{\text {stoich }}\right)$, implying that soot formation or complete combustion may be avoided if mixtures fall below these levels. For example, since $Z_{\text {stoich }}$ is closer to the injector nozzle for biodiesel, both axially and radially, shortening and narrowing the flame is expected. Also, since both fuels have comparable lift-off lengths, a smaller percentage of fuel jet mixtures fall above $\mathrm{Z}_{\text {soot }}$ for biodiesel, thereby reducing downstream soot formation. Indeed, the higher $\mathrm{Z}_{\text {soot }}$ for biodiesel partially compensates for the fact that its lift-off length is slightly less than that of diesel.

Aside from fuel oxygenation effects on mixture stoichiometry, the molecular structure of the fuel will also strongly affect the progression of soot formation downstream of the lift-off length, as discussed in detail in Ref. [17]. Inside of the diffusion flame, a partially premixed fuel-rich combustion zone forms soot precursors that are the foundation for soot growth downstream. As noted above, the transition from high- 
temperature, fuel-rich combustion near the lift-off length to soot formation does not happen immediately. Distances between the lift-off length and the first soot formation easily exceed $10 \mathrm{~mm}$, with greater distances evident for biodiesel compared to diesel. Soot precursor and soot formation pathways within these regions are complex, and dependent upon mixture stoichiometry, original molecular structure, local mixture temperature, and residence time $[57,58,17,18]$. Soot formation commences after the formation and growth of condensed ring aromatics (PAHs) [67, 68].

While a biodiesel (methyl ester) fuel has a higher sooting propensity than other oxygenated fuels because of a non-optimal $\mathrm{C}=\mathrm{O}$ structural group [69], its molecular structure is still much less prone to form soot compared to typical diesel fuel. The D2 diesel fuel used in this study already contains $27 \%$ of aromatics, whereas biodiesel is aromatics free. Biodiesel contains carbon-oxygen bonds quite difficult to break, inhibiting the formation of carbon-carbon double and triple bonds that lead to the formation of acetelyne and benzene (single ring aromatic). The longer distance required for soot growth is apparent in Figure 13, if comparing a constant threshold (e.g., 2 ppm) between biodiesel and diesel. The longer distance also means that more residence time is required before the first soot formation or any subsequent soot growth. During this time, continual mixing and entrainment of ambient oxygen and combustion products proceeding from diffusion flame occurs whilst moving downstream, which can suppress the total soot growth. Since biodiesel fuel is oxygenated and has higher $Z_{\text {stoich, }}$, this entrained oxygen curtails soot growth more quickly than a hydrocarbon fuel, thereby also shortening the residence time. Ultimately, it is the combination of (1) fuel oxygenation effects on mixing and (2) fuel molecular structure benefits that produces much lower soot for biodiesel compared to diesel.

\section{Conclusion}

To study the effect of biodiesel fueling on the combustion processes of a diesel engine, a set of optical diagnostics have been applied to a soy methyl ester free spray under both reactive $\left(15 \% \mathrm{O}_{2}\right)$ and nonreactive $\left(0 \% \mathrm{O}_{2}\right)$ environments. Experiments were conducted in an optically accessible, constant-volume vessel at ambient conditions representative of a modern diesel engine $\left(22.8 \mathrm{~kg} / \mathrm{m}^{3}, 900-1000 \mathrm{~K}, 6.0-6.7\right.$ $\mathrm{MPa}, 15 \% \mathrm{O}_{2}$ ), comparing biodiesel to conventional \#2 diesel. High-speed imaging and other diagnostics provided: (1) time-resolved liquid-phase penetration, (2) vapor-phase penetration, (3) ignition timing and location, (4) quasi-steady lift-off length, (5) flame boundaries, and (6) the in-flame soot distribution. These results provide a comprehensive understanding of the spray mixing and vaporization processes, coupled to a more fundamental understanding of the spray and combustion characteristics of biodiesel, when used as a direct replacement for conventional diesel.

Major conclusions drawn from this work are summarized as follows:

1- The liquid-phase penetration of biodiesel stabilized at a distance about $30 \%$ farther downstream of the injector nozzle than with conventional \#2 diesel at different ambient temperature conditions $(900 \mathrm{~K}$ and $1000 \mathrm{~K})$. This result is consistent with the higher distillation temperature range of biodiesel. Comparing reacting and inert conditions showed no significant difference in liquid length for either fuel, in part because the liquid length was upstream of the flame lift-off length. 
2- The vapor-phase penetration rate is very similar between \#2 diesel and biodiesel, with the biodiesel jet penetrating slightly more. Higher penetration for biodiesel could be caused by a better discharge coefficient of injection or a lower spreading angle, but these factors, as well as the penetration difference itself are within experimental uncertainty. The similarity in penetration suggests a similar fuel mixture fraction distribution exists for diesel and biodiesel, which can be estimated using a 1-D mixing model. Because biodiesel is oxygenated, and has the same mixture fraction distribution as diesel, it necessarily has a lower stoichiometry (equivalence ratio) distribution compared to diesel fuel.

3- Under inert conditions, the vapor penetration of biodiesel at 900 and $1000 \mathrm{~K}$ overlap perfectly. Under reacting conditions (15\% oxygen), the jet penetrates more quickly in the axial direction compared to an inert, vaporizing jet.

4- The ignition delay and lift-off length were slightly shortened when using biodiesel. The lift-off length and ignition delay results in increasing order are: $\mathrm{BD}(1000 \mathrm{~K})<\mathrm{D} 2(1000 \mathrm{~K})<\mathrm{BD}(900$ $\mathrm{K})<\mathrm{D} 2(900 \mathrm{~K})$. This result follows the cetane rating of the two fuels, with the biodiesel fuel sample for this study having a higher cetane number than the \#2 diesel.

5- Spatially-resolved contours of soot volume fraction were measured by combining line-of-sight laser extinction and laser-induced incandescence, providing the first quantitative in-situ soot measurements of a biodiesel spray at engine conditions. At the $1000 \mathrm{~K}$ ambient condition, a factor of 5 reduction in peak soot volume fraction was observed when using biodiesel instead of conventional diesel, while a factor of 10 reduction was observed at the $900 \mathrm{~K}$ ambient condition.

6- With very similar lift-off lengths, the reduced soot formation for biodiesel can be attributed to its fuel oxygenation, combined with a molecular structure less prone to soot formation. Because of fuel oxygenation, mixtures are less fuel-rich at the center of jet for biodiesel. Consequently, premixed combustion occurs at lower stoichiometry, closer to the jet center, and confined by a more narrow diffusion flame. In addition, biodiesel chemical composition, with no aromatics and with strong oxygen-carbon bonds, tends to reduce its sooting propensity. The longer time for soot inception and growth, combined with entrained oxygen during this period, ultimately limits the soot formation significantly for biodiesel compared to diesel.

The database completed for biodiesel, including spray vaporization, mixing, ignition, combustion, and soot distribution, offers a valuable benchmark for CFD development with biofuels. In particular, we offer the first quantitative soot volume fraction measurements within reacting fuel sprays at diesel engine conditions, which are needed to develop soot models specific to methyl ester biofuels. These data are available online at [49].

\section{Acknowledgments}

The research was performed at the Combustion Research Facility, Sandia National Laboratories, Livermore, California. Sandia is a multiprogram laboratory operated by Sandia Corporation, a Lockheed Martin Company, for the United States Department of Energy's National Nuclear Security.

The authors would also like to acknowledge the Spanish Ministry of Science and Innovation for supporting Jean-Guillaume Nerva's visiting research, through the OPTICOMB project (TRA2007-67961C03-01). 


\section{References}

1. Energy technology perspectives - scenarios \& strategies to 2050, International Energy Agency, 2006.

2. Official Journal of the European Union, Directive 2003/30/EC of the European parliament and of the council of 8 May 2003 on the promotion of the use of biofuels or other renewable fuels for transport.

3. Monyem A., Van Gerpen J.H., "The effect of biodiesel oxidation on engine performance and emissions". Biomass \& Bioenergy, Vol. 20, pp. 317-325, 2001.

4. Lapuerta M., Armas O., Rodríguez-Fernández J., "Effect of biodiesel fuel on diesel engine emissions". Progress in Energy and Combustion Science, Vol. 34, pp. 198-223, 2008.

5. Fisher B.T., Knothe G., Mueller C.J., "Liquid-Phase Penetration under Unsteady In-Cylinder Conditions: Soy- and Cuphea-Derived Biodiesel Fuels Versus Conventional Diesel”. Energy \& Fuels, Vol. 24, pp. 5163-5180, 2010.

6. Fang T., Lin Y.-C., Foong T.M., Lee C.-F., "Biodiesel combustion in an optical HSDI diesel engine under low load premixed combustion conditions". Fuel, Vol. 88, pp. 2154-2162, 2009.

7. Pastor J.V., García-Oliver J.M., Nerva J.-G., Giménez B. "Fuel Effect on the Liquid-Phase Penetration of an Evaporating Spray Under Transient Diesel-like Conditions". Fuel, doi:10.1016/j.fuel.2011.05.006, 2011.

8. Higgins B. S., Mueller C. J., Siebers D. L., "Measurements of fuel effects on liquid-phase penetration in DI sprays, SAE Paper 1999-01-0519, SAE Trans. 108 (3) pp. 630- 643, 1999.

9. Fisher B.T., Mueller C.J., "Liquid penetration length of heptamethylnonane and trimethylpentane under unsteady in-cylinder conditions". Fuel, Vol. 89, pp. 2673-2696, 2010.

10. Siebers D.L., Higgins B.S., "Flame Lift-Off on Direct-Injection Diesel Sprays Under Quiescent Conditions". SAE Paper 2001-01-0530, 2001.

11. Li L., Zhang X., Wu Z., Deng J., Huang C., "Experimental Study of Biodiesel Spray and Combustion Characteristics". SAE Paper 2006-01-3250, 2006.

12. Senda J., Ikeda T., Haibara T., Wada Y., Fujimoto H., "Spray and Combustion Characteristics of Reformulated Biodiesel with Mixing of Lower Boiling Point Fuel". SAE Paper 2007-01-0621, 2007.

13. Genzale C.L., Pickett L.M., Kook S., "Liquid Penetration of Diesel and Biodiesel Sprays at LateCycle Post-Injection Conditions”. SAE Paper 2010-01-0610, 2010.

14. Kim H. J., Park S. H., Suh H. K., Lee C. S., "Atomization and evaporation characteristics of biodiesel and dimethyl ether compared to diesel fuel in a high-pressure injection system". Energy \& Fuels. Vol. 23, pp. 1734-1742, 2009.

15. Suh H.K., Roh G.H., Lee C.S., "Spray and combustion characteristics of biodiesel/diesel blended fuel in a direct injection common-rail diesel engine". Trans. ASME J Eng Gas Turbines Power, Vol. 130 pp. 2807-2815, 2008.

16. Allocca L., Mancaruso E., Montanaro A., Vaglieco B. M., Vassallo A, "Renewable Biodiesel/Reference Diesel Fuel Mixtures Distribution in Non-Evaporating and Evaporating Conditions for Diesel Engines". SAE Paper 2009-24-0054, 2009. 
17. Pickett L.M., Siebers D.L., "Soot formation in diesel fuel jets near the lift-off length". Int. J. Engine Res., Vol. 7 (2), pp. 103-130, 2006.

18. Pickett L.M., Siebers D.L., "Fuel Effects on Soot Processes of Fuel Jets at DI Diesel Conditions". SAE Paper 2003-01-3080, 2003.

19. Venugopal, R., Abraham, J., "A Review of Fundamental Studies Relevant to Flame Lift-off in Diesel Jets," SAE Paper 2007-01-0134, SAE Transactions, Journal of Engines, 116:132-151, 2007.

20. Wu Y., Huang R., Liu Y., Leick M., Lee C.-F. F., "Effect of Ambient Temperature on Flame Liftoff and Soot Formation of Biodiesel Sprays". SAE Paper 2010-01-0606, 2010.

21. Pickett L.M., Siebers D.L., Idicheria C.A, "Relationship between ignition processes and the liftoff length of diesel fuel jets". SAE Paper 2005-01-3843, 2005.

22. Pickett L.M., Kook S., Persson H., Andersson O., "Diesel fuel jet lift-off stabilization in the presence of laser-induced plasma ignition". Vol. 32, pp. 2793-2800, 2009.

23. Yoo C.S., Richardson E.S., Sankaran R., Chen J.H., "A DNS study on the stabilization mechanism of a turbulent lifted ethylene jet flame in highly-heated coflow". Proc. Combust. Inst., Vol. 33, pp. 1619-1627, 2011.

24. Musculus M.P., Dec J.E., Tree D.R., "Effects of fuel parameters and diffusion flame lift-off on soot formation in a heavy-duty DI diesel engine". SAE Paper 2002-02-0889, 2002.

25. Pastor J.V., Payri R., Gimeno J., Nerva J.-G., "Experimental Study on RME Blends: Liquid-Phase Fuel Penetration, Chemiluminescence, and Soot Luminosity in Diesel-Like Conditions". Energy \& Fuels, Vol. 23, pp. 5899-5915, 2009.

26. Dec J.E., Espey C., "Ignition and Early Soot Formation in a D.I. Diesel Engine Using Multiple 2D Imaging Diagnostics”. SAE Paper 950456, 1995.

27. Dec J.E., “A Conceptual Model of DI Diesel Combustion Based on Laser-Sheet Imaging”. SAE Paper 970873, 1997.

28. Suhre B.R., Foster D.E., "In-cylinder soot deposition rates due to thermophoresis in a direct injection diesel engine”. SAE Paper 921629, 1992.

29. Kittelson D.B., Ambs J.L., Hadjkacem, H., "Particulate emissions from diesel engines: influence of in-cylinder surfaces". SAE Paper 900645, 1990.

30. Pickett L.M., Siebers D.L., "Non-Sooting, Low Flame Temperature Mixing-Controlled DI Diesel Combustion". SAE Paper 2004-01-1399, 2004.

31. Benajes J., Molina S., Novella R., Amorim R., "Study on Low Temperature Combustion for Light-Duty Diesel Engines". Energy \& Fuels, Vol. 24, pp. 355-364, 2010.

32. Pickett L.M., Siebers D.L., "An investigation of diesel soot formation processes using microorifices," Proceedings of the Combustion Institute, 29 (1):655-662, 2002.

33. Siebers D.L., Pickett L.M., in: Conference on Thermofluidynamic Processes in Diesel Engines, Valencia, 2002.

34. Pickett L.M., Siebers D.L., "Soot in Diesel Fuel Jets: Effects of Ambient Temperature, Ambient Density, and Injection Pressure". Combustion \& Flame, Vol. 138, pp. 114-135, 2004.

35. Mueller C.J., Boehman A.L., Martin G.C., "An experimental investigation of the origin of increased NOx emissions when fueling a heavy-duty compression-ignition engine with soy biodiesel". SAE Paper 2009-01-1792, SAE Int. J. Fuels Lubr, 2009.

36. Beatrice C.,Bertoli C., Del Giacomo N., Guido C., Migliaccio M., "In-cylinder Soot Evolution Analysis in a Transparent Research DI Diesel Engine Fed by Oxygenated Fuels". SAE Paper 2002-01-2851, 2002. 
37. Cheng A.S., Upatnieks A., Mueller C.J., "Investigation of the impact of biodiesel fuelling on NOx emissions using an optical direct injection diesel engine”. Int. J. Engine Res., Vol.7, pp. 297-318, 2006.

38. Cheng A.S., Upatnieks A., Mueller C.J. "Investigation of Fuel Effects on Dilute, MixingControlled Combustion in an Optical Direct-Injection Diesel Engine” Energy \& Fuels, Vol. 21, pp. 1989-2002, 2007.

39. Beatrice C., Capaldi P., Del Giacomo N., Guido C., Mancaruso E., Vaglieco B.M., "Analysis of Impact of Diesel Fuel/Biodiesel Blends on a Modern Diesel Combustion System Performance by Means of Injection Test Rig, Optical and Real SC Engine Experiments". SAE Paper 2009-010484, 2009.

40. Klein-Douwel R.J.H., Donkerbroek A.J., Van Vliet A.P., Boot M.D., Somers L.M.T., Baert R.S.G., Dam N.J., Ter Meulen J.J.," Soot and chemiluminescence in diesel combustion of bioderived, oxygenated and reference fuels". Proc. Combust. Inst., Vol. 32, pp. 2817-2825, 2009.

41. Fang T., Lee C.F., "Bio-Diesel Effects on Combustion Processes in an HSDI Diesel using Advanced Injection Strategies". Proceedings of the Combustion Institute, Vol. 32, pp 2785-2792, 2009.

42. Mueller C.J., Martin G.C., "Effects of oxygenated compounds on combustion and soot evolution in a DI diesel engine: Broadband natural luminosity imaging”. SAE Paper 2002-01-1631, SAE Trans., Vol. 111, pp. 518-537, 2002.

43. Svensson K.I., Richards M.J., Mackrory A.J., Tree D.R., "Fuel Composition and Molecular Structure Effects on Soot Formation in Direct-Injection Flames Under Diesel Engine Conditions", SAE Paper 2005-01-0381, 2005.

44. Payri F., Pastor J.V., Nerva J.-G., García-Oliver J.M., "Lift-off length and KL extinction measurements of biodiesel and Fischer-Tropsch fuels under quasi-steady diesel engine conditions", SAE Int. J. Engines 4:2278-2297, August 2011. SAE Paper 2011-24-0037, 2011.

45. Siebers D.L., "Liquid-Phase Fuel Penetration in Diesel Sprays". SAE Paper 980809, 1998.

46. Pickett L.M., Genzale C.L., Bruneaux G., Malbec L.M. Hermant L., Christiansen C., Schramm J., "Comparison of Diesel Spray Combustion in Different High-Temperature, High-Pressure Facilities”. SAE Paper 2010-01-2106, 2010.

47. Kook S., Pickett L.M., "Liquid length and vapor penetration of conventional, Fischer-Tropsch, coal-derived, and surrogate fuel sprays at high-temperature and high-pressure ambient conditions". Fuel (2011), doi:10.1016/j.fuel.2011.10.004.

48. Naber J.D., Siebers D.L., "Effects of Gas Density and Vaporization on Penetration and Dispersion of Diesel Sprays". SAE Paper 960034, SAE Trans J Engines, Vol. 105, pp. 82-111, 1996.

49. Engine Combustion Network experimental data archive, http://www.sandia.gov/ECN/

50. Pickett L.M., Kook S., Williams T.C., "Visualization of Diesel Spray Penetration, Cool-Flame, Ignition, High-Temperature Combustion, and Soot Formation Using High-Speed Imaging". SAE Paper 2009-01-0658, 2009.

51. Settles G.S., Schlieren and Shadowgraph Techniques, Springer-Verlag, 2001.

52. Pastor J.V., Payri R., García-Oliver J.M., Nerva J.-G., "Schlieren Measurements of the ECNSpray A Penetration under Inert and Reacting Conditions". SAE Paper 2012-01-0456, 2012.

53. Dec J.E., Espey C., "Chemiluminescence Imaging of Autoignition in a Di Diesel Engine". SAE Paper 982685, 1998. 
54. Higgins B.S., Siebers D.L., "Measurement of the Flame Lift-Off Location on DI Diesel Sprays Using OH Chemiluminescence”. SAE Paper 2001-01-0918, 2001.

55. Musculus M.P., Pickett L.M., "Diagnostic considerations for optical laser-extinction measurements of soot in high-pressure transient combustion environments". Combustion \& Flame, Vol. 141, pp. 371-391, 2005.

56. Williams, T.C., Shaddix, C.R., Jensen, K.A., and Suo-Anttila, J.M., "Measurement of the Dimensionless Extinction Coefficient of Soot within Laminar Diffusion Flames", Int. J. Heat Mass Trans 50:1616-1630, 2007.

57. Pickett L.M., Idicheria C.A. in Conference on Thermofluidynamic Processes in Diesel Engines, Valencia, Spain, 2006.

58. Idicheria C.A., Pickett L.M., "Soot Formation in Diesel Combustion under High-EGR Conditions". SAE Paper 2005-01- 3834, 2005.

59. Kook S., Pickett L.M., "Soot volume fraction and morphology of conventional and surrogate jet fuel sprays at 1000-K and 6.7 MPa ambient conditions". Proc. Combust. Inst., Vol. 33, pp. 29112918, 2011.

60. Pickett L.M., Manin J., Genzale C.L., Siebers D.L., Musculus M.P.B., Idicheria C.A., "Relationship Between Diesel Fuel Spray Vapor Penetration/Dispersion and Local Fuel Mixture Fraction," SAE Int. J. Engines 4:764-799; doi:10.4271/2011-01-0686.

61. Musculus M.P., Kattke K., "Entrainment Waves in Diesel Jets". SAE Paper 2009-01-1355. SAE Int. J. Engines, Vol. 2, pp. 1170-1193, 2009.

62. Siebers D.L., "Scaling Liquid-Phase Fuel Penetration in Diesel Sprays Based on Mixing-Limited Vaporization". SAE Paper 1999-01-0528, 1999.

63. Verhoeven D., Vanhemelryck J.L., Baritaud T., "Macroscopic and ignition Characteristics of High Pressure Sprays of Single-Component Fuels”. SAE Paper 981069, 1998.

64. Desantes J.M., Pastor J.V., García-Oliver J.M., and Pastor, J.M., "A 1D model for the description of mixing-controlled reacting diesel sprays," Combustion \& Flame Vol. 156, pp. 234-249, 2009.

65. Siebers D.L., "Recent Developments on Diesel Fuel Jets Under Quiescent Conditions". Flow and Combustion in Reciprocating Engines, Springer Berlin Heidelberg, 2009.

66. Idicheria C.A. and Pickett L.M., "Ignition, soot formation, and end-of-combustion transients in diesel combustion under high-EGR conditions," Int. J. Engine Res., 12(4), pp. 376-392, 2011.

67. Aizawa T. and Kosaka H., "Investigation of early soot formation process in a diesel spray flame via excitation-emission matrix using a multi wavelength laser source". Int. J. Engine Res., 9(1), pp. 79-97, 2008.

68. Bruneaux G., "Combustion structure of free and wall-impinging diesel jets by simultaneous laser induced fluorescence of formaldehyde, polyaromatic hydrocarbons, and hydroxides". Int. J. Engine Res., 9(3), pp. 249-265, 2008.

69. Mueller C.J., Pitz W.J., Pickett L.M., Martin G.C., Siebers D.L., and Westbrook C.K., "Effects of Oxygenates on Soot Processes in DI Diesel Engines: Experiments and Numerical Simulations". SAE Paper 2003-01-1791, 2003.

\section{Nomenclature}

2D: two-dimensional 
ASI: after start of injection

ASTM: American standard testing and material

BD: biodiesel (soy-methyl ester)

BP: band pass

$\mathrm{C}_{\mathrm{a}}$ : area coefficient

CCD: charge-coupled device

$\mathrm{C}_{\mathrm{d}}$ : discharge coefficient

CMOS: complementary metal oxide semi-conductor

$\mathrm{CN}$ : cetane number

$\mathrm{C}_{\mathrm{V}}$ : discharge coefficient of the injector nozzle

CW: continuous wave

D2: American conventional \#2 diesel

EGR: exhaust gas recirculation

$F$ : lens focal length

FAME: fatty acid methyl ester

$\mathrm{f}_{\mathrm{v}}$ : soot volume fraction

FWHM: full width at half maximum

HeNe: helium-neon

ID: ignition delay

INFL: integrated natural flame luminosity

KL: $\quad$ K: coefficient of extinction; L: length of the laser path

LHV: lower heating value

LL: liquid length

LOL: lift-off length

$\mathrm{Nd}$ :YAG: neodymium-doped yttrium aluminum garnet

$\mathrm{NO}_{\mathrm{X}}$ : nitrogen oxides

$\mathrm{OH}$ : hydroxyl radical

(P)LII: (planar) laser-induced incandescence

PM: particle matter

$\theta$ : full spreading angle

SEM: scanning electron microscopy

SINL: spatial integrated soot luminosity

TDC: top dead center

UHC: unburnt hydrocarbons

$\mathrm{Z}_{\text {evap }}$ : mixture fraction of liquid evaporation

$\mathrm{Z}_{\text {soot }}$ : mixture fraction of soot formation

$\mathrm{Z}_{\text {stoich }}$ : stoichiometric mixture fraction 


\section{LIST OF TABLES}

\begin{tabular}{lll}
\hline Ambient Conditions & Non-reacting & Reacting \\
\hline $\mathrm{O}_{2} / \mathrm{N}_{2} / \mathrm{CO}_{2} / \mathrm{H}_{2} \mathrm{O}$ [Volume \%] & $\mathbf{0} / 89.71 / 6.52 / 3.77$ & $\mathbf{1 5} / 75.15 / 6.23 / 3.62$ \\
Pressure $[\mathrm{MPa}]$ & $6.0-6.7$ & $6.0-6.7$ \\
Temperature $[\mathrm{K}]$ & $900-1000$ & $900-1000$ \\
Density $\left[\mathrm{kg} \cdot \mathrm{m}^{-3}\right]$ & 22.8 & 22.8 \\
\hline
\end{tabular}

Table 1. Ambient conditions

\begin{tabular}{ll}
\hline Injection settings & \\
\hline Type & Bosch common-rail \\
Nozzle & Single-hole, KS1.5/86, mini-sac \\
Nozzle diameter (Nominal/Measured) & $90 / 90.8 \mu \mathrm{m}$ \\
Injection pressure & $150 \mathrm{MPa}$ \\
Fuel temperature (SME/\#2 Diesel) & $363 / 373 \mathrm{~K}$ \\
Discharge coefficient (SME/\#2 Diesel) & $0.94 / 0.91$ \\
\hline
\end{tabular}

Table 2. Injector characteristics and fuel temperature

\begin{tabular}{|c|c|c|}
\hline Fuel Properties & $\begin{array}{l}\text { Soy Methyl- } \\
\text { Esther }\end{array}$ & \#2 Diesel \\
\hline Density at $288 \mathrm{~K}\left[\mathrm{~kg} \cdot \mathrm{m}^{-3}\right]$ & 877 & 843 \\
\hline Density expected @ 373 K [kg.m³] & 823 & 766 \\
\hline Kinematic Viscosity at $313 \mathrm{~K}\left[\mathrm{~mm}^{2} . \mathrm{s}^{-1}\right]$ & 3.98 & 2.35 \\
\hline Lower Heating Value $\left[\mathrm{MJ}_{\mathrm{kg}}{ }^{-1}\right]$ & 37.4 & 43.0 \\
\hline Aromatics [Volume \%] & 0 & 27 \\
\hline
\end{tabular}


$\mathrm{C} / \mathrm{H}$ and $\mathrm{C} / \mathrm{O}$ mass ratios

$6.48 / 7.05$

$6.53 / \infty$

Cetane Number

51

46

$\mathrm{Z}_{\text {stoich }}\left(15 \% \mathrm{O}_{2}\right)$

0.054

0.046

$Z_{\text {soot }}{ }^{1}$

0.105

0.089

Table 3. Fuel properties

Mixture fraction at critical sooting equivalence ratio. Defined as $\phi=2.0$ for conventional diesel [32] and $\phi_{\Omega}=2.0$ for biodiesel ( $\phi_{\Omega} \equiv$ oxygen equivalence ratio [49]).

\begin{tabular}{llll}
\hline $\begin{array}{l}\text { Constituent } \\
\text { name }\end{array}$ & $\begin{array}{l}\text { Constituent } \\
\text { abbreviation }\end{array}$ & $\begin{array}{l}\text { Chemical } \\
\text { formula }\end{array}$ & $\%$ \\
\hline Methyl palmitate & $\mathrm{C} 16: 0$ & $\mathrm{C}_{17} \mathrm{H}_{34} \mathrm{O}_{2}$ & 11 \\
Methyl stearate & $\mathrm{C} 18: 0$ & $\mathrm{C}_{19} \mathrm{H}_{38} \mathrm{O}_{2}$ & 4.0 \\
Methyl oleate & $\mathrm{C} 18: 1$ & $\mathrm{C}_{19} \mathrm{H}_{36} \mathrm{O}_{2}$ & 25 \\
Methyl linoleate & $\mathrm{C} 18: 2$ & $\mathrm{C}_{19} \mathrm{H}_{34} \mathrm{O}_{2}$ & 53 \\
Methyl linolenate & $\mathrm{C} 18: 3$ & $\mathrm{C}_{19} \mathrm{H}_{32} \mathrm{O}_{2}$ & 7 \\
\hline
\end{tabular}

Table 4. Soy-derived biodiesel composition per the fuel manufacturer.

\begin{tabular}{|c|c|c|c|c|c|}
\hline Optical setup & $\begin{array}{l}\text { Mie- } \\
\text { scatter }\end{array}$ & Schlieren & Luminosity & PLII & $O H^{*}$ \\
\hline Laser/lighting & $\begin{array}{ll}532 & \mathrm{~nm} \\
\mathrm{CW} & \\
(2 \mathrm{~W}) & \end{array}$ & Broadband arc lamp & $\begin{array}{l}\text { Natural } \\
\text { emission }\end{array}$ & $\begin{array}{l}532 \mathrm{~nm} \\
(100 \mathrm{~mJ})\end{array}$ & $\begin{array}{l}\text { Natural } \\
\text { emission }\end{array}$ \\
\hline Camera & \multicolumn{3}{|c|}{ High-speed CMOS (Phantom v7.1) } & \multicolumn{2}{|c|}{ Intensified CCD (Xybion) } \\
\hline Lens focal length & $50 \mathrm{~mm}$ & & & $105 \mathrm{~mm}$ & $105 \mathrm{~mm}$ UV \\
\hline Lens f-stop & $\mathrm{f} / 1.2$ & $f / 1.2$ & $\mathrm{f} / 1.2$ & $f / 2.8$ & $f / 4.5$ \\
\hline $\begin{array}{l}\text { Filter center } \lambda \\
(\text { FWHM) }\end{array}$ & $\begin{array}{l}532 \mathrm{~nm} \\
(10 \mathrm{~nm})\end{array}$ & $532 \mathrm{~nm} 0^{\circ}$ inc. mirror & None & $<450 \mathrm{~nm}$ & $\begin{array}{l}310 \mathrm{~nm} \\
(10 \mathrm{~nm})\end{array}$ \\
\hline Framing Period & $20 \mu \mathrm{s}$ & $20 \mu \mathrm{s}$ & $20 \mu \mathrm{s}$ & $\mathrm{n} / \mathrm{a}$ & $\mathrm{n} / \mathrm{a}$ \\
\hline Exposure Duration & $10 \mu \mathrm{s}$ & $2 \mu \mathrm{s}$ & $16 \mu \mathrm{s}$ & $50 \mathrm{~ns}$ & $3 \mathrm{~ms} / 200 \mu \mathrm{s}$ \\
\hline Resolution & $512 \times 64$ & $256 \times 88$ & $256 \times 112$ & $640 \times 480$ & $640 \times 480$ \\
\hline Pixels/mm & 3.75 & 2.59 & 2.81 & 6.77 & 7.23 \\
\hline
\end{tabular}


Table 5. Optical imaging setups.

\begin{tabular}{lll}
\hline Ignition Delay [us ASOI] & Soy Methyl-Esther & \#2 Diesel \\
\hline $900 \mathrm{~K}$ (Chemiluminescence/Pressure) & $709 / 660$ & $782 / 761$ \\
$1000 \mathrm{~K}$ (Chemiluminescence/Pressure) & $377 / 389$ & $510 / 510$ \\
Ignition Position [mm] & Soy Methyl-Esther & \#2 Diesel \\
\hline $900 \mathrm{~K}$ (Chemiluminescence) & 34.0 & 35.9 \\
\hline $1000 \mathrm{~K}$ (Chemiluminescence) & 23.7 & 26.4 \\
\hline
\end{tabular}

Table 6. Ignition delays and position proceeding from the chemiluminescence imaging and pressure trace analysis, after correction for the speed of sound.

\section{LIST OF FIGURES}

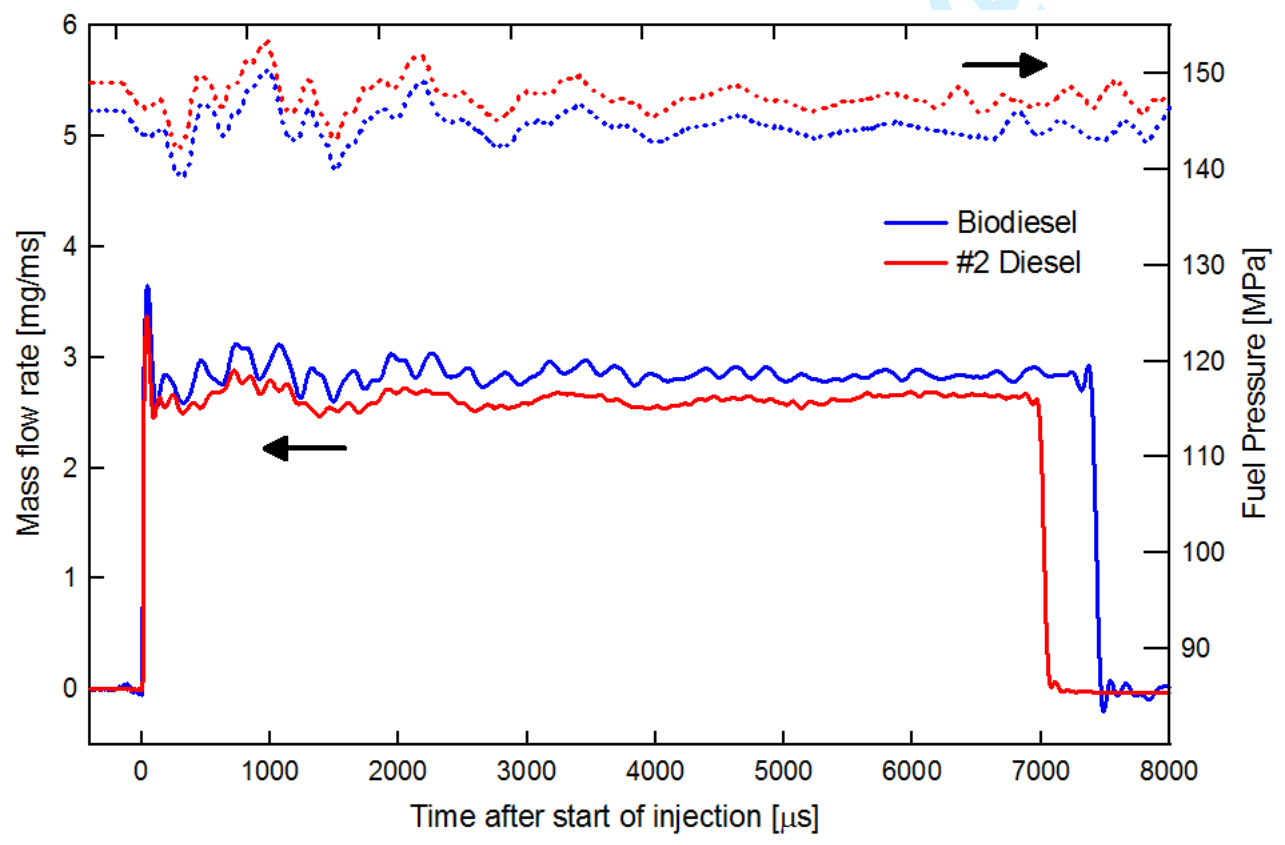


Figure 1. Mass rate of injection of diesel \#2 and SME biodiesel for the conditions of Table 1. Fuel pressure in the line at $24 \mathrm{~cm}$ from the nozzle is shown at the top.

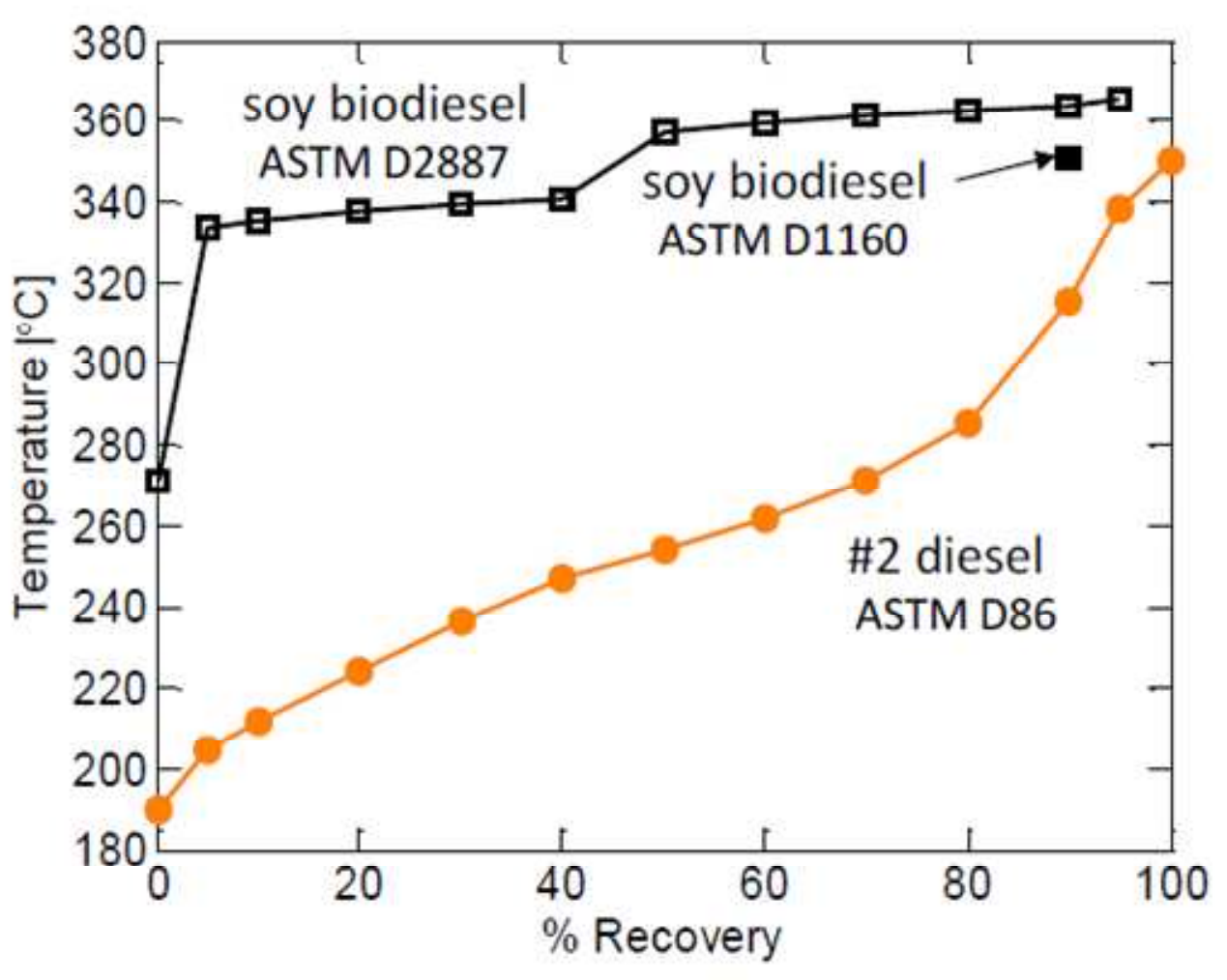

Figure 2. Distillation curves for \#2 diesel and soy-based biodiesel fuels used in this study. Note that the distillation curves are produced using different ASTM distillation methods, as shown. The 90\% boiling point for the biodiesel fuel, measured by the ASTM D1160 distillation method, is also given. 


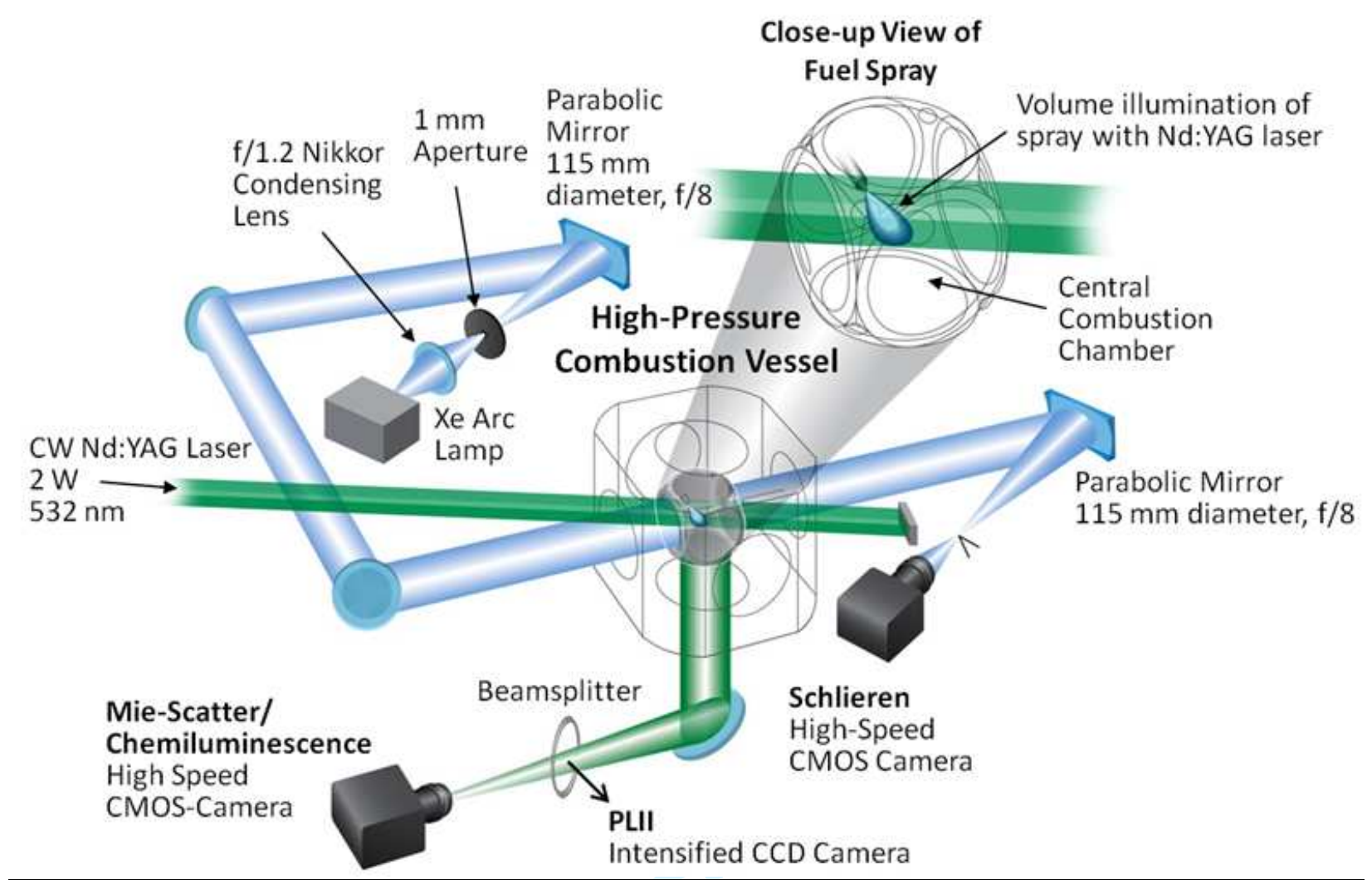

Figure 3. Optical setup for vapor, liquid, and combustion luminosity imaging.

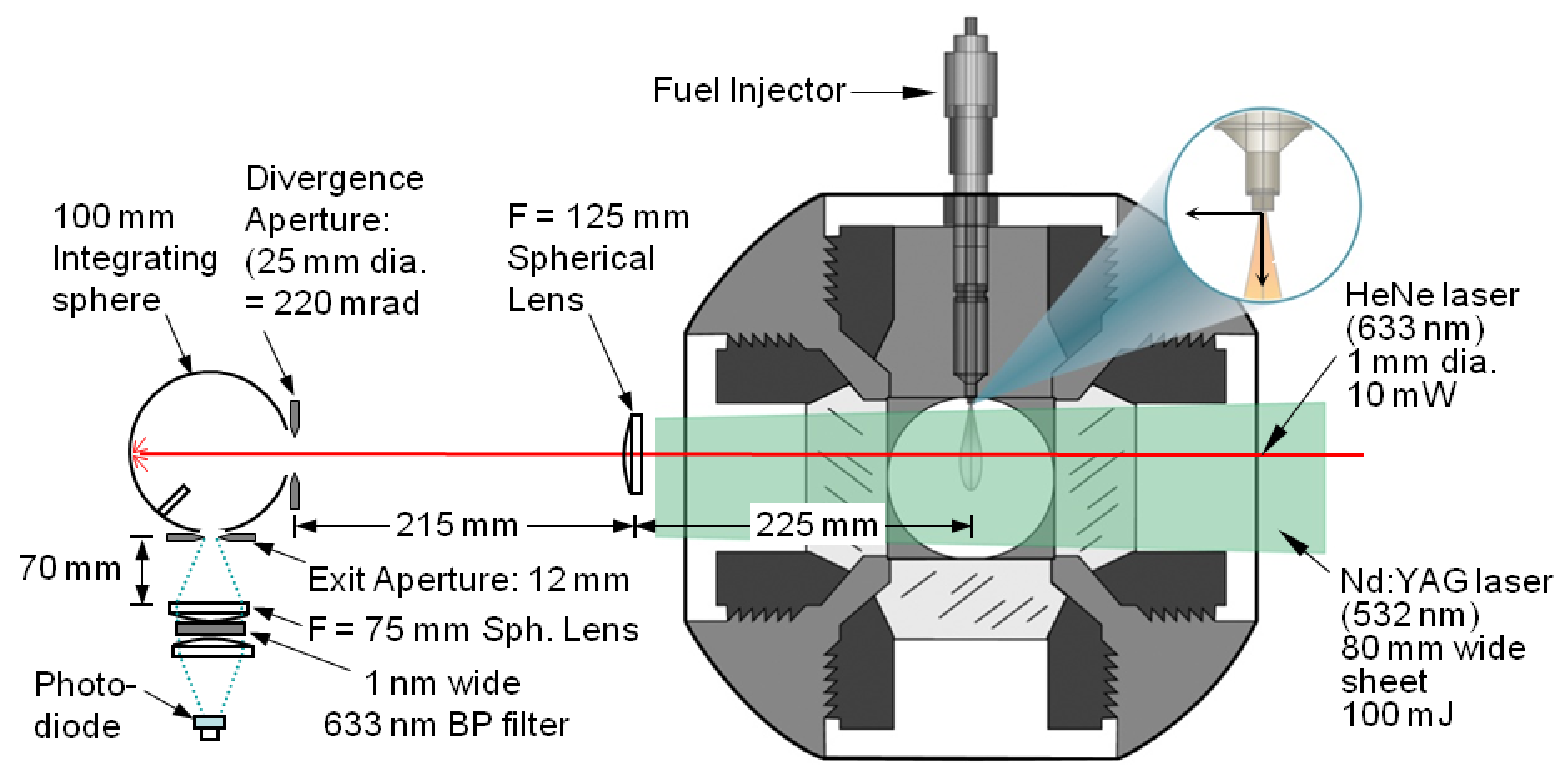

Figure 4. Simultaneous laser extinction and planar laser-induced incandescence imaging setup 


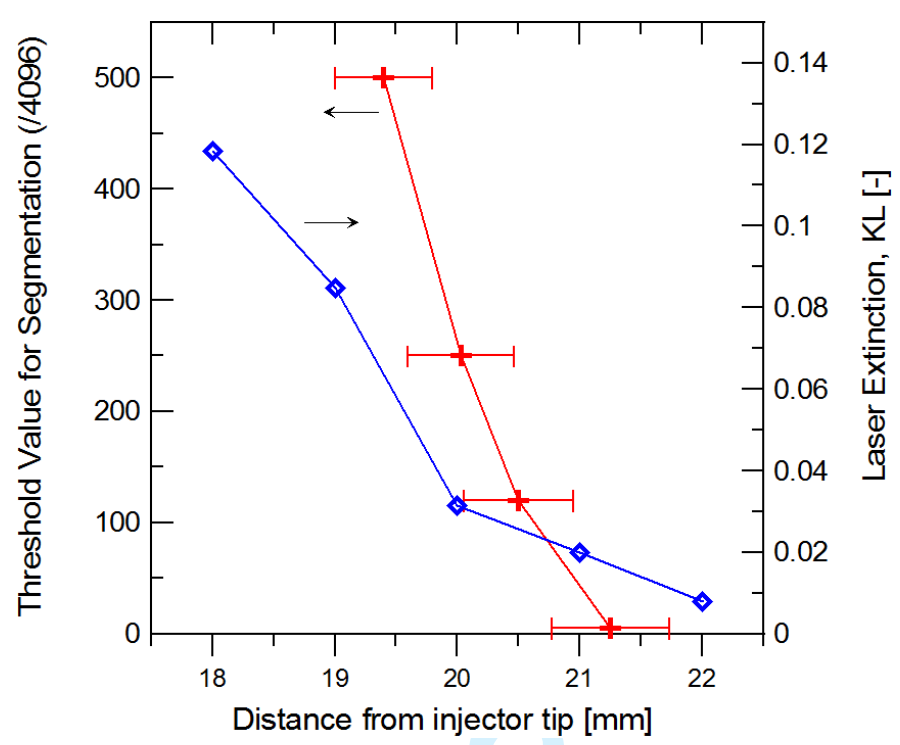

Figure 5. Laser extinction measurements in the liquid spray tip region compared to the liquid length obtained with different thresholds for Mie-scattering image segmentation. Biodiesel, $900 \mathrm{~K}$.

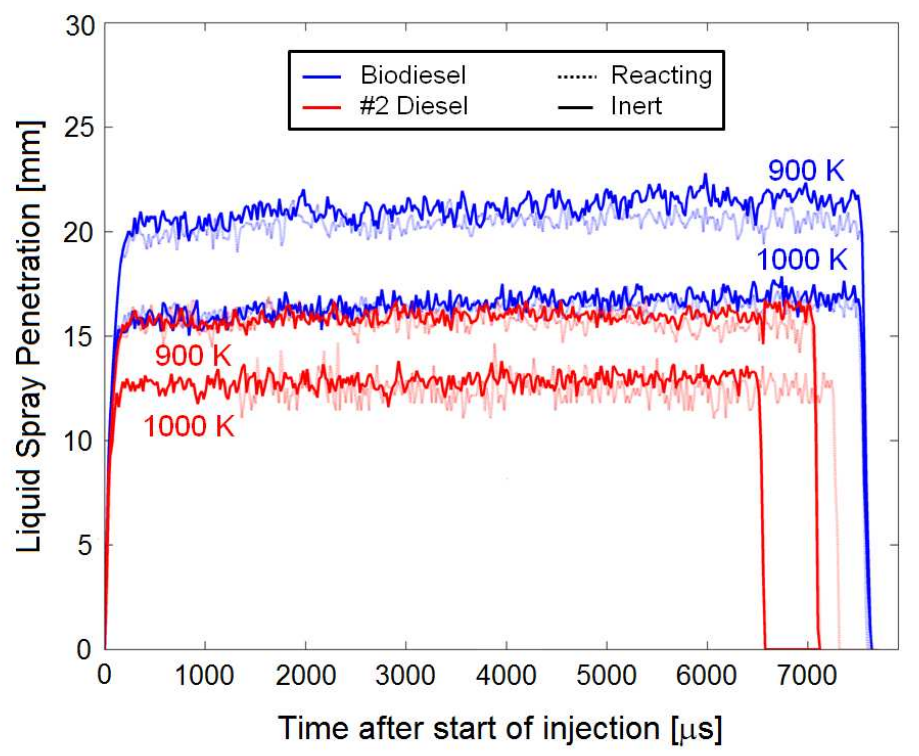

Figure 6. Liquid-phase penetration of conventional diesel \#2 and biodiesel under both reactive and non-reactive environment at 2 different ambient temperatures. $\mathrm{LL}(\mathrm{D} 2,900 \mathrm{~K})=15.8 \mathrm{~mm}$; $\mathrm{LL}(\mathrm{D} 2$, $1000 \mathrm{~K})=12.6 \mathrm{~mm} ; \mathrm{LL}(\mathrm{BD}, 900 \mathrm{~K})=21.2 \mathrm{~mm} ; \mathrm{LL}(\mathrm{BD}, 1000 \mathrm{~K})=16.6 \mathrm{~mm}$ 


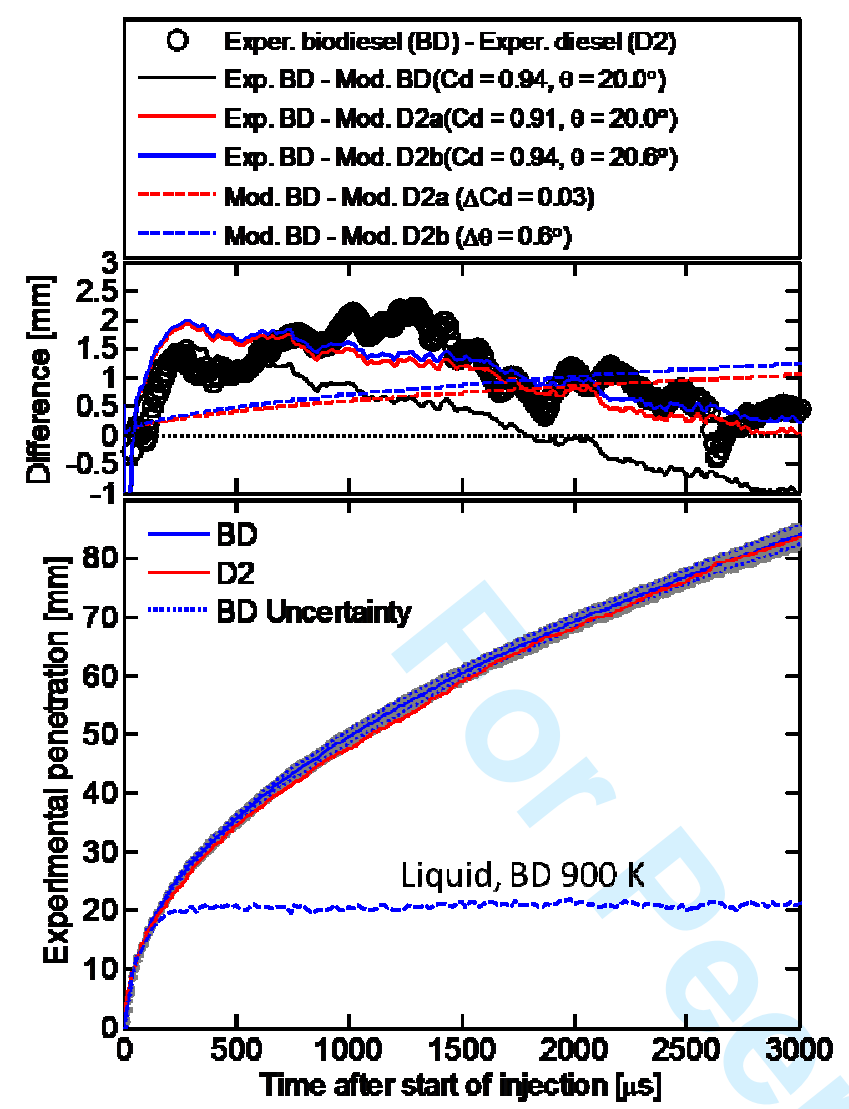

Figure 7. Experimental and modeling results of the jet vapor penetration for both diesel and biodiesel non-reactive conditions at $900 \mathrm{~K}$. (top) Difference of biodiesel experimental penetration with respect to diesel, or penetration modeling predictions with different discharge coefficient $\left(\mathrm{C}_{\mathrm{d}}\right)$ or different full spreading angle $(\theta)$.

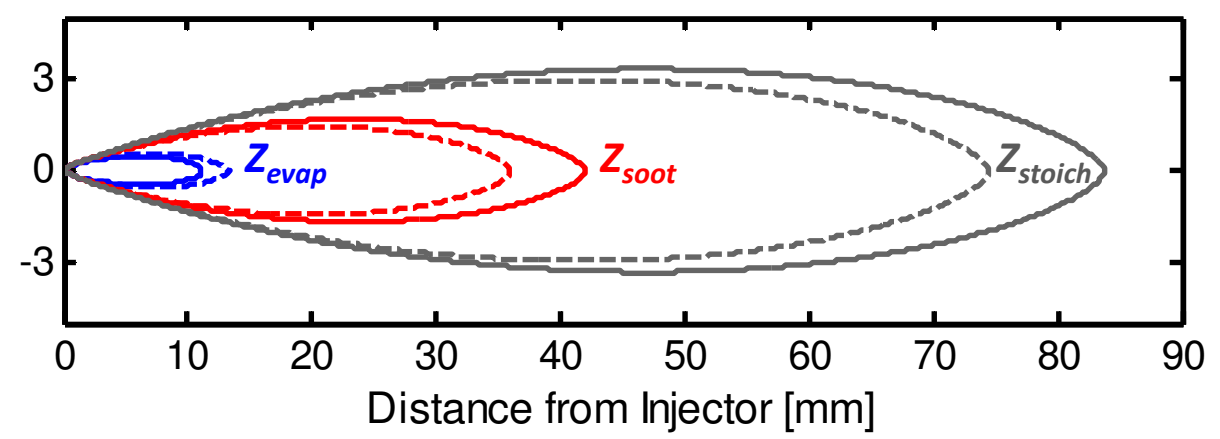

Figure 8. Results of spray calculations using biodiesel (dashed line) and \#2 diesel (continuous line) at 900 K. Inputs BD: s.a. $=20^{\circ}, C_{a}=0.99, C_{d}=0.94$. D2: s.a. $=20^{\circ}, C_{a}=0.99, C_{d}=0.91$. Nozzle diameter $(0.0908 \mathrm{~mm})$ and fuel density at injection temperature from Table 3. From left to right: the evaporative, sooting and stoichiometric surfaces. 


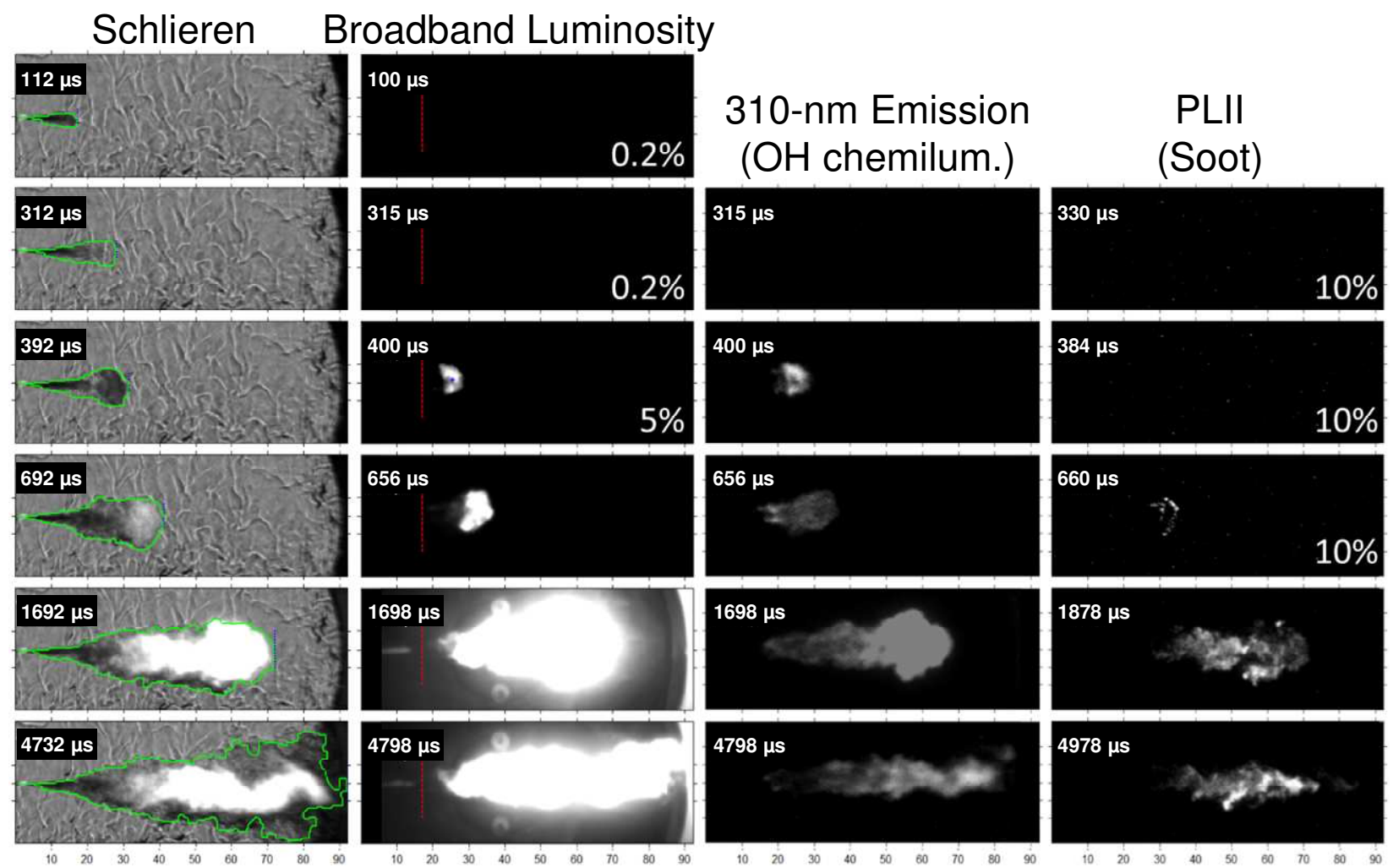

Figure 9. Multi-diagnostic image sequences of the combustion of a biodiesel spray at $1000 \mathrm{~K}$. Left: green border is vapor boundary. Left middle: steady lift-off length is dashed red line. If given at the image lower right, the image display range is shown as a percentage of full scale, otherwise the display range is full scale. 


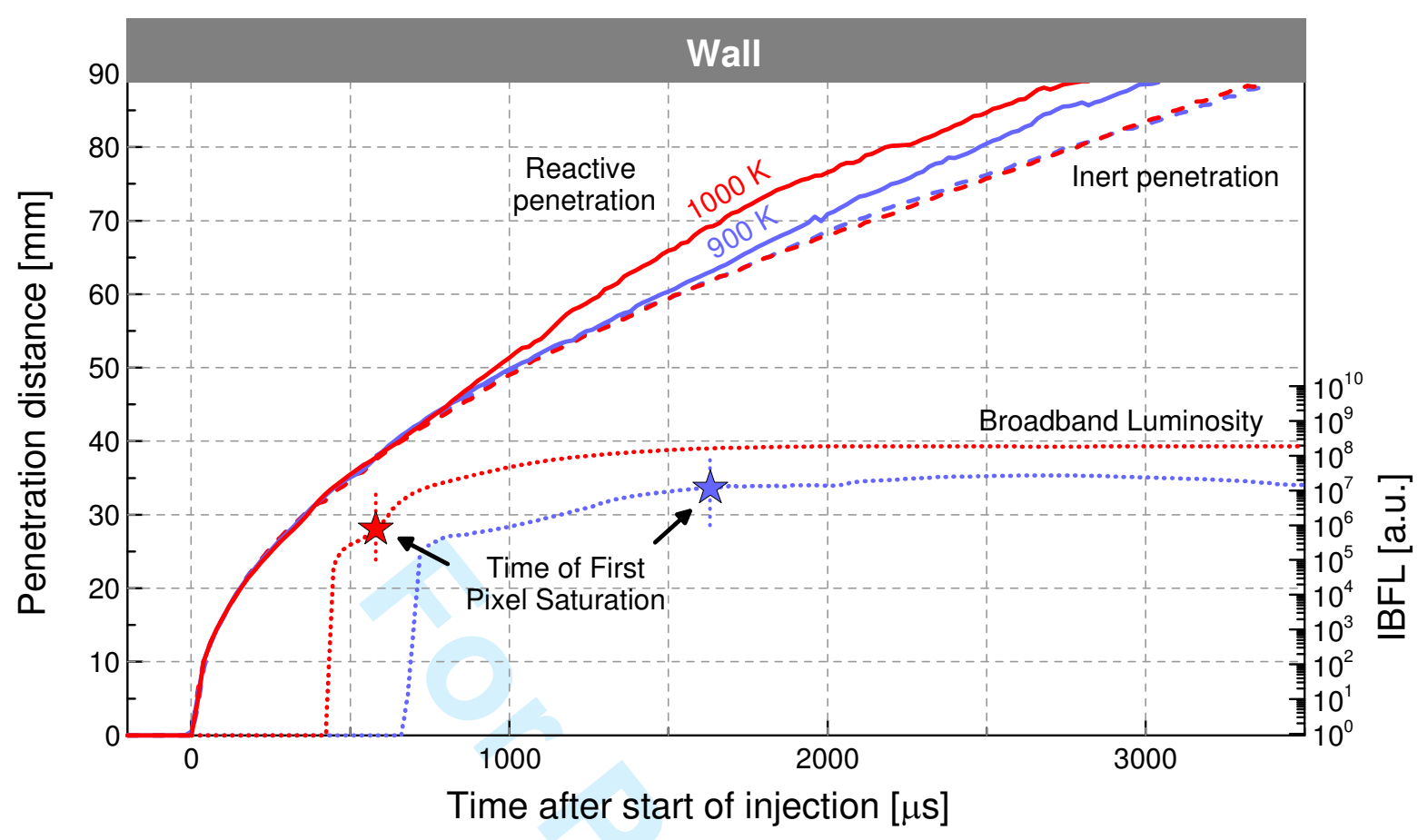

Figure 10. Vapor-phase penetration of the biodiesel spray under both reactive and non-reactive environment at 900 and $1000 \mathrm{~K}$. Spatially integrated broadband flame luminosity is calculated by the integration of image digital intensity levels and is represented on a logarithmic scale at the right.

$900 \mathrm{~K}$

$1000 \mathrm{~K}$
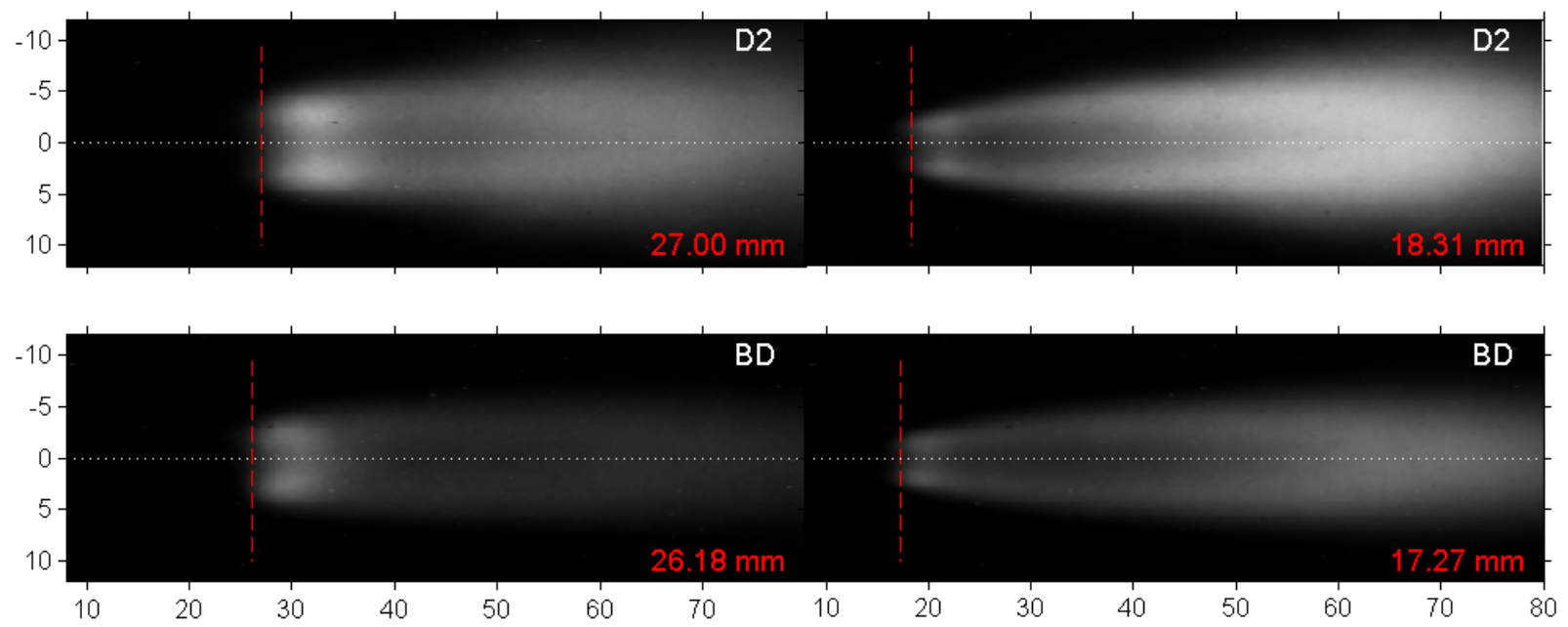

Figure 11. Ensemble average of the $\mathrm{OH}$ chemiluminescence images for both diesel and biodiesel at two ambient temperature conditions. Lift-off length is represented in red dashed line with the value indicated at the lower right. 


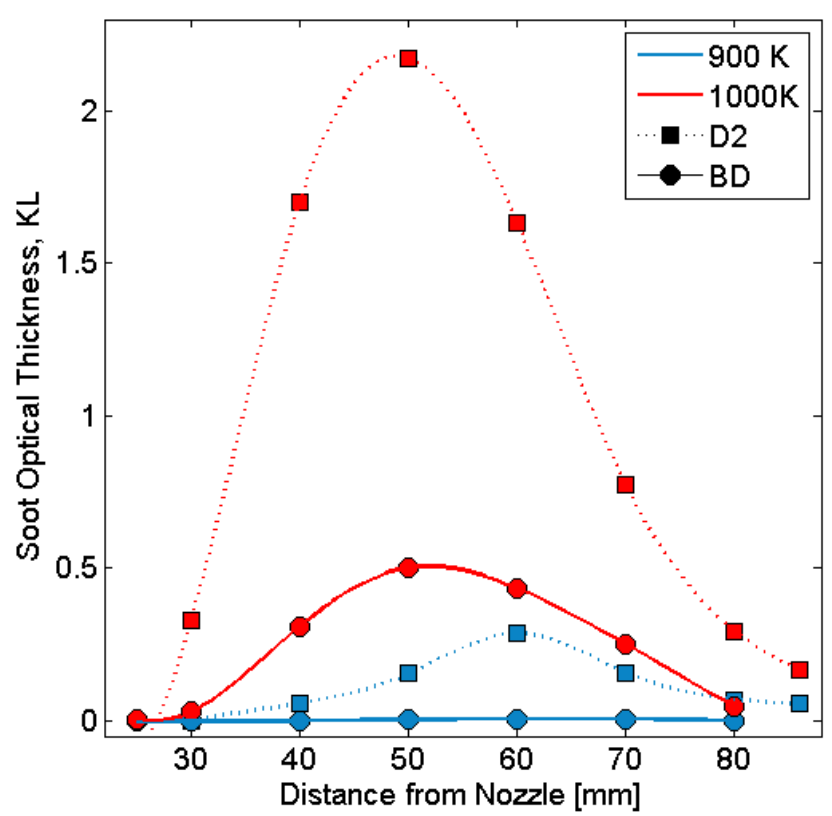

Figure 12. Laser extinction measurements along the flame axis.

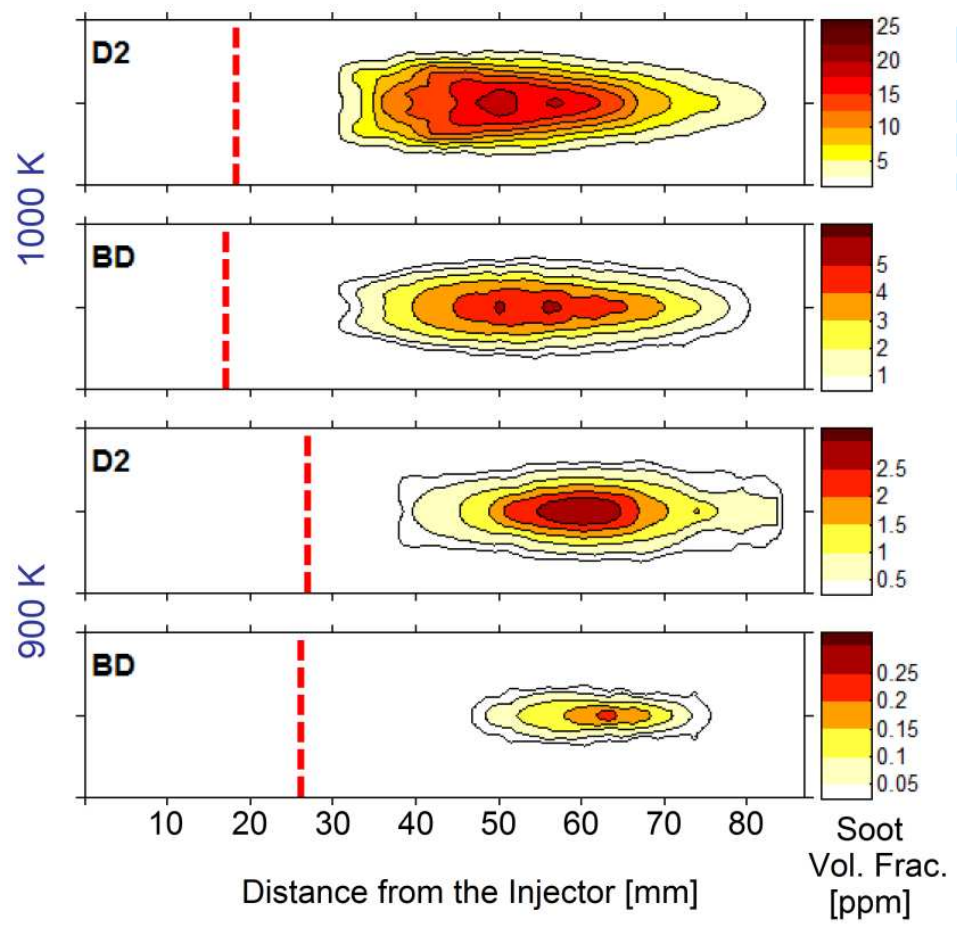

Figure 13. Soot volume fraction distributions in the transversal cut of the flame. Lift-off length is represented by vertical dashed line. 